\title{
Cladistics
}

\section{Phylogenetic relationships among superfamilies of Hymenoptera}

\author{
Michael J. Sharkey ${ }^{\mathrm{a}, *}$, James M. Carpenter ${ }^{\mathrm{b}}$, Lars Vilhelmsen ${ }^{\mathrm{c}}$, John Heraty ${ }^{\mathrm{d}}$, Johan \\ Liljeblad $^{\mathrm{e}}$, Ashley P.G. Dowling ${ }^{\mathrm{f}}$, Susanne Schulmeister ${ }^{\mathrm{b}}$, Debra Murray ${ }^{\mathrm{g}}$, Andrew R. \\ Deans $^{\mathrm{h}}$, Fredrik Ronquist ${ }^{\mathrm{i}}$, Lars Krogmann ${ }^{\mathrm{j}}$ and Ward C. Wheeler ${ }^{\mathrm{b}}$

\begin{abstract}
${ }^{a}$ Department of Entomology, University of Kentucky, Lexington, KY 40502, USA; ${ }^{b}$ Division of Invertebrate Zoology, American Museum of Natural History, Central Park West at 79th Street, New York, NY 10024, USA; ${ }^{c}$ Natural History Museum of Denmark, Universitetsparken 15, 2100 Copenhagen Ø, Museet-Bygn.11, 2-4-429, Denmark; ${ }^{2}$ Department of Entomology, University of California, Riverside, CA 92521, USA; ${ }^{e}$ Species Information Centre, Swedish Agricultural University, SE-75007 Uppsala, Sweden; ${ }^{f}$ Department of Entomology, University of Arkansas, 319 Agriculture Building, Fayetteville, AR 72701, USA; ${ }^{g}$ Department of Biology, Duke University, Durham, NC 27708, USA; ${ }^{h}$ Department of Entomology, North Carolina State University, Campus Box 7613, 2301 Gardner Hall, Raleigh, NC 27695 7613, USA; ${ }^{i}$ Department of Entomology, Swedish Museum
\end{abstract} \\ of Natural History, SE-10405 Stockholm, Sweden; ${ }^{j}$ Staatliches Museum für Naturkunde, Rosenstein 1, 70191 Stuttgart, Germany
}

Accepted 7 June 2011

\begin{abstract}
The first comprehensive analysis of higher-level phylogeny of the order Hymenoptera is presented. The analysis includes representatives of all extant superfamilies, scored for 392 morphological characters, and sequence data for four loci (18S, 28S, COI and EF-1 $\alpha$ ). Including three outgroup taxa, 111 terminals were analyzed. Relationships within symphytans (sawflies) and Apocrita are mostly resolved. Well supported relationships include: Xyeloidea is monophyletic, Cephoidea is the sister group of Siricoidea $+[$ Xiphydrioidea + (Orussoidea + Apocrita $)]$; Anaxyelidae is included in the Siricoidea, and together they are the sister group of Xiphydrioidea + (Orussoidea + Apocrita); Orussoidea is the sister group of Apocrita, Apocrita is monophyletic; Evanioidea is monophyletic; Aculeata is the sister group of Evanioidea; Proctotrupomorpha is monophyletic; Ichneumonoidea is the sister group of Proctotrupomorpha; Platygastroidea is sister group to Cynipoidea, and together they are sister group to the remaining Proctotrupomorpha; Proctotrupoidea s. str. is monophyletic; Mymarommatoidea is the sister group of Chalcidoidea; Mymarommatoidea + Chalcidoidea + Diaprioidea is monophyletic. Weakly supported relationships include: Stephanoidea is the sister group of the remaining Apocrita; Diaprioidea is monophyletic; Ceraphronoidea is the sister group of Megalyroidea, which together form the sister group of [Trigonaloidea (Aculeata + Evanioidea)]. Aside from paraphyly of Vespoidea within Aculeata, all currently recognized superfamilies are supported as monophyletic. The diapriid subfamily Ismarinae is raised to family status, Ismaridae stat. nov.
\end{abstract}

(C) The Will Henning Society 2011.

Hymenoptera have traditionally been divided into two suborders, "Symphyta" (sawflies) and Apocrita, with the latter subdivided into "Parasitica" (parasitoids) and Aculeata (stinging wasps, bees, and ants). Even before the advent of cladistic principles, "Symphyta" were not generally considered a monophyletic group. The division between "Parasitica" and Aculeata was usually based on behavior, that is parasitic versus predatory behaviour, but the biology of many Aculeata

\footnotetext{
*Corresponding author: E-mail address: msharkey@uky.edu
}

is ectoparasitoid. Whereas Aculeata have a diagnostic synapomorphy (the sting), none has been forthcoming for Parasitica, and the likelihood that this group is paraphyletic has been widely accepted.

Phylogenetic research on higher level relationships within the order as a whole has been based primarily on morphological data. Intuitive approaches that included character diagnoses began with a series of papers by Rasnitsyn (1969, 1980, 1988) and Königsmann (1976, 1977, 1978a,b). Rasnitsyn's research was not cladistic, but incorporated much fossil data and was original. Königsmann's research mostly comprised characters taken from the literature, and although ostensibly cladistic, the data were analyzed intuitively, with little 
resolution obtained at the superfamily level within the "Parasitica" grade.

Rasnitsyn's (1988) summary paper came to be used as the starting point for quantitative phylogenetic studies of higher level relationships across the Hymenoptera. Ronquist et al. (1999) revisited the 1988 character list, and coded it into a numerical cladistic matrix. However, their analyses of the matrix resulted in little resolution, especially within the Apocrita, and thus they were unable to corroborate many of the relationships suggested by Rasnitsyn. Nevertheless, the Ronquist et al. (1999) data set was used in the combined molecular/morphological analyses of the higher-level relationships of the Hymenoptera as a whole (Carpenter and Wheeler, 1999) and Apocrita (Dowton and Austin, 2001).

The matrix of Ronquist et al. (1999) represents Rasnitsyn's (1988) interpretations of many character systems, but in many cases these are not cladistic in nature. Rasnitsyn's interpretations owed much to fossils and many character definitions are not ideal for recent taxa. Moreover, the idiosyncratic manner in which Rasnitsyn (1988) analyzed his data allowed him to ignore homoplasy and down-weight characters on an ad hoc basis. The characters were coded for hypothesized ground-plans instead of representing observations, and many characters, obviously including those published after 1988, were not included. Sharkey and Roy (2002) critically examined the characters of the matrix that pertain to wings ( 37 of the 169 characters). They edited these but did not deal with other morphological characters, which in many cases need to be reconsidered. Detailed analyses of the Symphyta by Vilhelmsen (2001) and Schulmeister et al. (2002) produced reasonably well resolved relationships of the basal lineages of Hymenoptera. In contrast, Sharkey and Roy's (2002) reanalysis of the Ronquist et al. (1999) data set (recoded wing characters) is representative of what little is known of apocritan superfamilial phylogenetic relationships, being largely unresolved.

Several molecular analyses have been published and in general these have focused on either the Apocrita (Dowton and Austin, 1994, 2001; Dowton et al., 1997; Castro and Dowton, 2006) or Symphyta (Schulmeister et al., 2002; Schulmeister, 2003). Davis et al. (2010) recently compiled a hymenopteran supertree at the family level from the studies published up until then. Besides the usual deficiencies of supertree analyses (see Goloboff and Pol, 2002), Davis et al. were unable to include the first HymAToL outputs relevant to higherlevel phylogeny of the Hymenoptera, i.e., Vilhelmsen et al. (2010) on mesosomal characters, including a multitude of muscular and other internal characters, and Heraty et al. (2011), presenting a large molecular analysis employing 28S, 18S, COI and EF-1 $\alpha$. Most recently, Sharanowski et al. (2010) proposed a novel hypothesis, based on EST analyses, in which Chalcidoi- dea were excluded from Proctotrupomorpha. However, although gene sampling was extensive, the taxon sampling was minimal (10 Hymenoptera) and the results varied depending on the method of analysis, thus we do not address their results further in this study. It is clear from previous research that both morphology and sequence data are informative. Combining these data sources into a comprehensive dataset including all hymenopteran superfamilies was an obvious path to take, and the focus of this paper.

\section{Materials and methods}

\section{Exemplar taxa}

The exemplar taxa include most of those in the molecular analyses of Heraty et al. (2011) and most of those in the morphological analysis of Vilhelmsen et al. (2010); however these two datasets did not have identical terminals. Because we did not have morphological data for most of the Heraty et al. (2011) outgroups, we included only those in the Vilhelmsen et al. (2010) dataset. We also deleted duplicates within genera, keeping those species with the most complete sequence data, i.e., we deleted two Orussus spp. and one Archaeoteleia. The terminals were also grossly overrepresentative of Aculeata relative to Parasitica, with 27 aculeates versus, for example, 11 Ichneumonoidea. The number of aculeate terminals was therefore reduced, to 11 , the same as Ichneumonoidea, selected by keeping all of those scored for most morphology, then cutting terminals scored only for molecular data, or scored mostly for molecular data, while still ensuring that each of the three aculeate superfamilies was represented by at least three terminals. This gave the final total of 111 terminals analyzed.

Significant differences from the Heraty et al. (2011) molecular data set are the inclusion of an additional two rare families, Peradeniidae and Austroniidae. Nine terminals were scored only for morphology, i.e., Urocerus, Dinapsis, Orgilus, Austronia, Peradenia, Phaenoserphus, Spalangia, Plumarius and Ycaploca. Six taxa were scored for sequence data only, viz. Scolia, Chalybion, Dasymutilla, Platygaster, Exallonyx and Myrmaromella.

\section{Morphological and behavioral data}

Three hundred and eighty-eight morphological and four behavioral characters are included. Morphological data are primarily from the 273 mesosomal characters of Vilhelmsen et al. (2010). To this foundation J.H., J.L. and L.V. added and scored 22 head characters (Vilhelmsen, in press), J.H. added and scored 46 mouthpart characters, A.R.D. added and scored 11 leg characters, M.J.S. added and scored nine metasomal, 21 wing, six 
ovipositor, and four behavioral characters. Most of the character states are illustrated elsewhere or they are easy to conceptualize.

\section{Molecular data}

The molecular data are detailed in Heraty et al. (2011). Alignment was not an issue for the COI and $\mathrm{EF}-1 \alpha$ data, but it was for the $18 \mathrm{~S}$ and $28 \mathrm{~S}$ data.

Two alignments were analyzed by Heraty et al. (2011), one aligned by eye and the other aligned to predicted secondary-structure. For various reasons, including the difficulty of applying secondary-structure to outgroup taxa, the eye-aligned data were preferred by Heraty et al. (2011) and these data are incorporated here. The eye alignment and secondary-structure alignment are almost identical in the stem regions. The major difference between them is that the former includes more of the variable loop regions, which were excluded in the secondary-structure alignment. The eye-aligned data produced a greater degree of resolution, especially within Aculeata. Overall, the results of both alignments were similar including the poorly supported relationships surrounding the Apocrita node. We also chose to include all of the nucleotide positions for COI and EF- $1 \alpha$, even though inclusion of third positions resulted in a much lower resolution than the parsimony analyses of Heraty et al. (2011). The molecular data set chosen herein is that with the greatest amount of informative sequence data.

Molecular sequences are deposited in Genbank; Genbank reference numbers can be found in Appendix 2 .

\section{Cladistic analyses}

The various data partitions originated as Nexus files, opened with the program Mesquite (Maddison and Maddison, 2009), exported in Hennig86/Nona format, and opened and combined with the program Winclada (Nixon, 2008). Data were exported from Winclada and analyzed in TNT (Goloboff et al., 2008). All analyses were the same, employing all four new technology search methods (Goloboff, 1999; Nixon, 1999), using the default settings in TNT, except: the ratchet weighting was probability $5 \%$ and there were 200 iterations; treedrifting used 50 cycles; tree-fusing used five rounds; minimum length was set to be hit 25 times. The use of new technology increases the rigor of the tree searches (see Freudenstein and Davis, 2010). Relative-support values ("RS" elsewhere in the text) were calculated using symmetric resampling (Goloboff et al., 2003), reported as frequency differences, with 1000 iterations employing new technology searches, all four search methods with the default settings. The symmetric resampling avoids either under- or overestimations of the actual group support in, comparison to, e.g., bootstrapping, while the frequency differences address the problem that group support in resampling does not necessarily vary with the frequency itself (Goloboff et al., 2003).

In an effort to determine where the cladistic signal originated, individual genes, all-genes combined and morphology-only were also analyzed separately. All data sets, i.e., individual genes, all-genes, morphology and total-evidence are deposited in TreeBase (http:// www.treebase.org).

\section{Results}

The tree in Fig. 1 is a simplified version of the totalevidence consensus tree of Fig. 2, with the superfamilies and Aculeata appearing as terminals. The former facilitates viewing of the inter-superfamilial relationships. Support values are shown on the branches. Branches with zero support collapsed in symmetric resampling, and these include a few basal branches of Apocrita.

The consensus of the results of analysis of the combined morphological and molecular data (Fig. 2) is well resolved, with Hymenoptera, Apocrita and Aculeata, and all but one superfamily appearing as monophyletic. Only Vespoidea, as expected (Pilgrim et al., 2008), does not appear in the consensus. The total-evidence symmetric-resampling tree is shown in Fig. 3.

Analysis of the morphological matrix produces a consensus that is poorly resolved (Fig. 4). The results of analysis using implied weighting (not shown) have slightly more resolution. This rather surprising result is due to the high percentage $(41 \%)$ of missing data in the

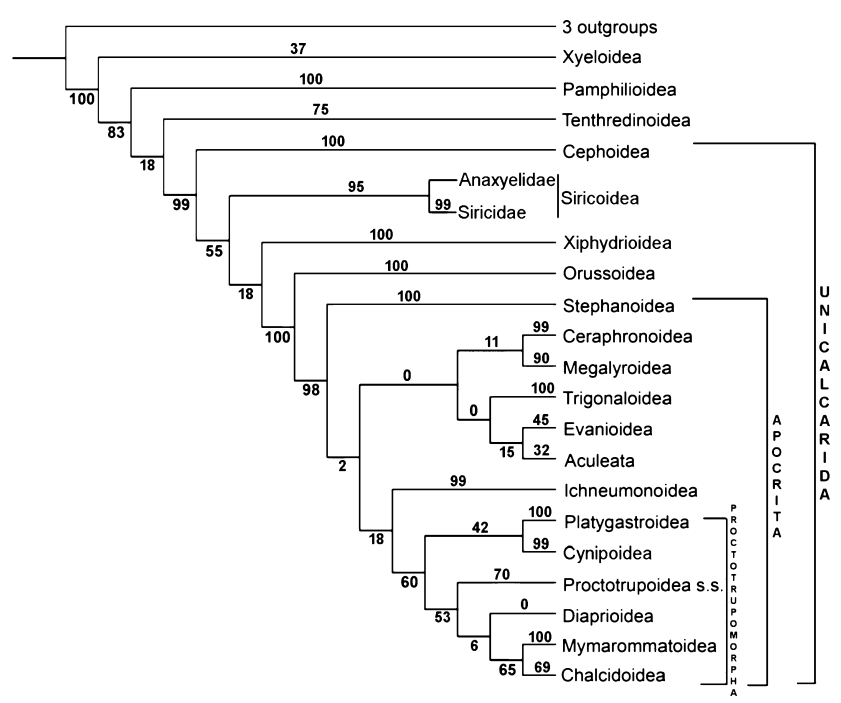

Fig. 1. Simplified total-evidence consensus. Values shown are frequency differences under symmetric resampling. 


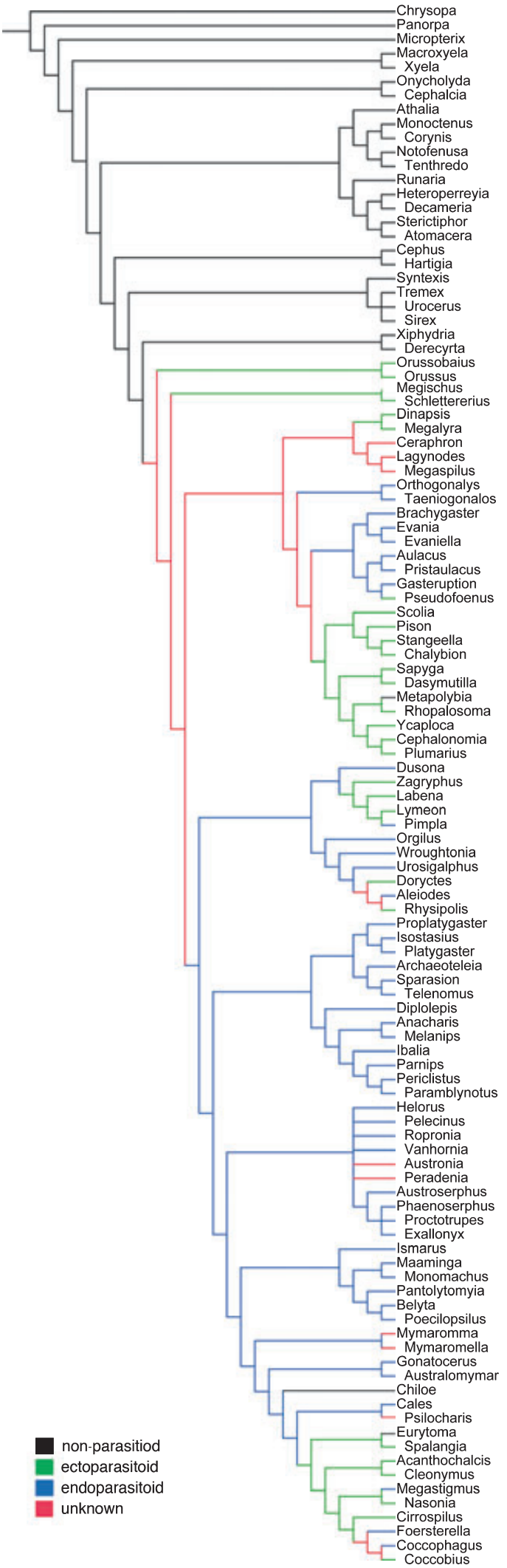

Fig. 2. Total-evidence consensus, based on 14 trees of length 27155 , $\mathrm{CI}=0.21, \mathrm{RI}=0.41$ morphological matrix. This high percentage is due to notable terminal mismatch (see Nixon and Carpenter, 1996) in the various morphological partitions. A total of 111 terminals are in the simultaneous analysis of morphological and molecular data, but each of the morphological partitions scored fewer than 100 terminals. The morphology-only symmetric-resampling tree is shown in Fig. 5 and here there is much more resolution, indicating a significant signal.

The consensus tree for the analyses of the combination of all four molecular markers (COI, EF- $1 \alpha, 18 \mathrm{~S}$ and $28 \mathrm{~S}$ ) is shown in Fig. 6. The consensus of eight trees is quite resolved; Hymenoptera appears as a monophyletic group, as do 17 of the 20 superfamilies represented by more than one exemplar. Figure 7 illustrates the molecule-only symmetric-resampling tree.

Figures 8 through 15 are the strict-consensus and symmetric-resampling trees for the individual genes, i.e., COI (Figs 8 and 9), 28S (Figs 10 and 11), EF-1 $\alpha$ (Figs 12 and 13) and 18S (Figs 14 and 15). We have included these to show where the various genes support, or contradict, our total-evidence result. With the exception of $28 \mathrm{~S}$ these results are unmodified. The data for $28 \mathrm{~S}$ that we included in the total-evidence matrix, result in a tree with some outgroups nested within Hymenoptera and with symphytans as derived Hymenoptera. For the sake of illustrating the strong signal present in the $28 \mathrm{~S}$ data when constrained by other data sources, we deleted the outgroups and rerooted on Macroxyela (Xyeloidea). In the original 18S tree, Micropterix was nested within Hymenoptera, therefore it was re-run without Micropterix to better show the signal of $18 \mathrm{~S}$ when Micropterix was constrained by other characters.

In the following text the interesting relationships in the cladogram of Figs 1 and 2 are discussed in detail. Morphological character states supporting the relationship are listed (refer to Appendix 1), and those that are highly consistent are written in full for each clade to save readers referring to the Appendix. Character states that were worthy of mention are those that are "uniquely derived", meaning that the character state is only derived once on the tree; however this allows for reversals. The former category includes non-homoplastic characters. Other character states mentioned are those that may have been derived convergently but if so only rarely and/or in distant regions of the tree.

\section{Xyeloidea}

History: Rasnitsyn (1988) proposed a paraphyletic Xyelidae with Macroxyelinae as the sister group to Tenthredinoidea and Xyelinae as sister group to the remaining Hymenoptera. This result was not obtained by Ronquist et al. (1999); they placed Xyelinae as the sister group to Macroxyelinae + remaining Hymenoptera 
GC values, 1000 replicates, cut $=1$ (tree 0 ) - Symmetric Resampling ( $P=33$ )

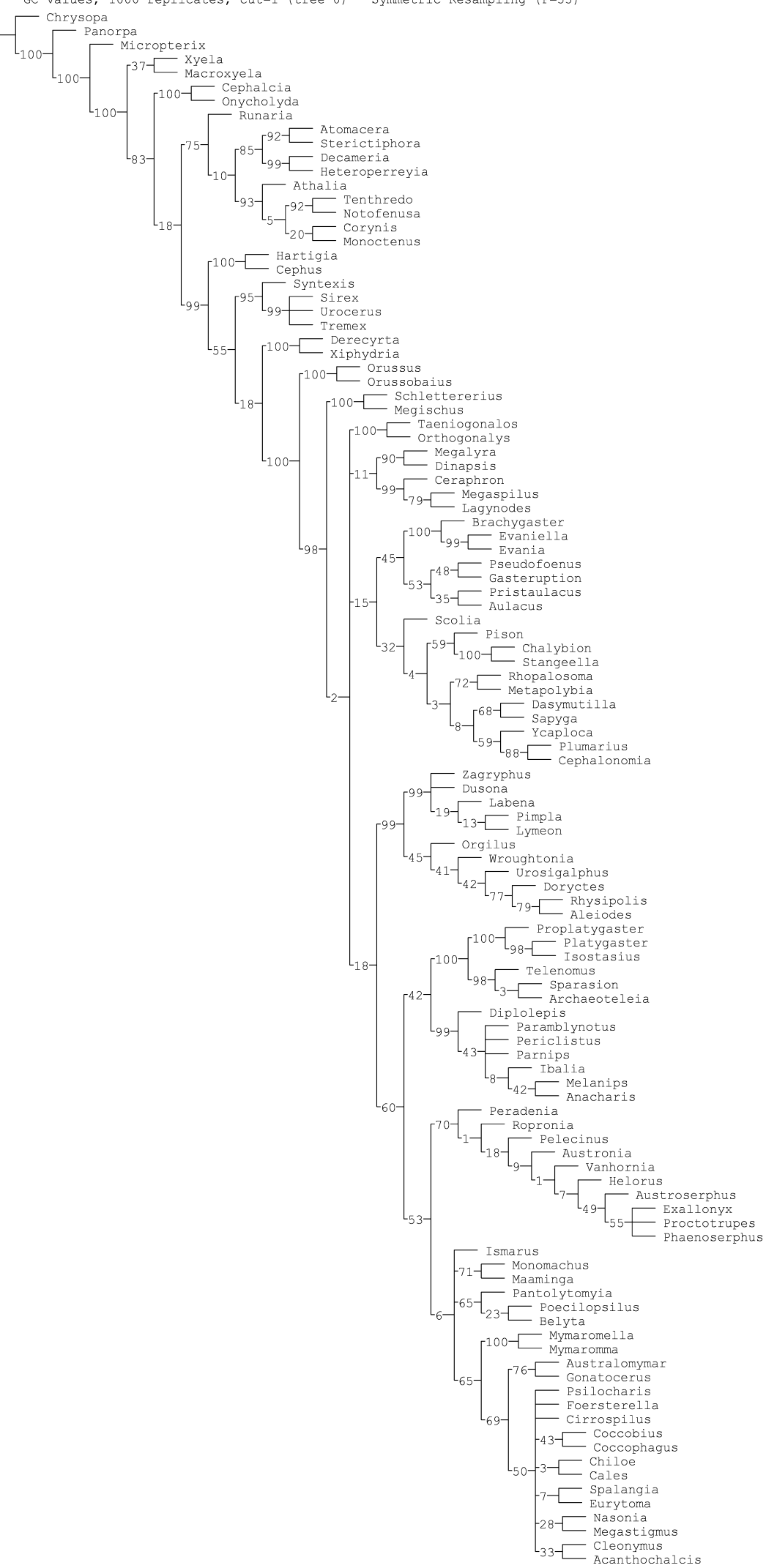

Fig. 3. Total-evidence support. 


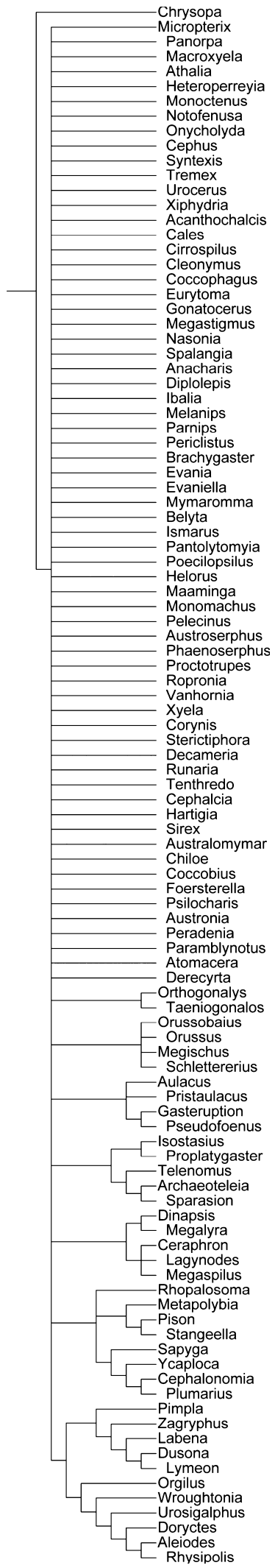

Fig. 4. Morphology consensus, based on 1000 trees (overflowed) of length $2329, \mathrm{CI}=0.20, \mathrm{RI}=0.66$. (including Tenthredinoidea). Vilhelmsen (1997) also failed to unequivocally corroborate Xyeloidea, whereas Vilhelmsen (2001) and Schulmeister (2003) retrieved Xyeloidea with some support. Xyeloidea was either monophyletic with strong support, or paraphyletic depending on the alignment and analysis type in Heraty et al. (2011).

Morphology: Present in the morphology-only tree with RS $=65$. Interestingly, there are no morphological character states supporting Xyeloidea in the totalevidence tree.

Genes: Present in the all-genes tree with RS $=56$.

Total-evidence: Present with RS $=37$.

Alternatives: Our COI support tree shows a similar relationship to that of Ronquist et al. (1999), with a weak RS value of 2. See history, above.

Conclusions: Strongly supported by molecular and morphological data in this analysis as well as in all analyses of Heraty et al. (2011) that included third codon positions.

Pamphilioidea + Tenthredinoidea + Cephoidea + Siricoidea + Xiphydrioidea + Orussoidea + Apocrita

History: This clade has been recovered by all recent morphological, molecular, and combined analyses, viz., Vilhelmsen (2001), Schulmeister et al. (2002), and Vilhelmsen et al. (2010). This grouping was supported in all analyses that excluded third codon positions in Heraty et al. (2011).

Total-evidence: Present with RS $=83$.

Morphology: Not present, although not contradicted, in the morphology-only consensus tree.

There are two uniquely derived synapomorphies (97, 167) and two with limited homoplasy.

95: cervical apodeme of propleural apodeme well developed (Vilhelmsen et al., 2010, fig. 40F).

97: laterocervicalia and propleuron completely fused and the cervical line absent. However, the cervical line is present in Blasticotomidae (Tenthredinoidea) (see Vilhelmsen, 2000).

113: anterior apodemes of profurca well developed and continuous with tendons (Vilhelmsen et al., 2010, figs $40 \mathrm{~F}, 41 \mathrm{~A})$.

167: postspiracular sclerite of mesopleuron present.

Genes: Present in the all-genes consensus tree with $\mathrm{RS}=22$. Present in the COI consensus tree with $\mathrm{RS}=91$. Not present, but not contradicted in the $28 \mathrm{~S}$ consensus tree. Present in the $28 \mathrm{~S}$ support-tree with a value of 25 . Present in the EF- $1 \alpha$ consensus tree with $\mathrm{RS}=98$. Contradicted in both $18 \mathrm{~S}$ consensus and support trees.

Alternatives: None.

Conclusions: Strongly supported by previous morphological studies and by the molecular data in our analysis. 
$\mathrm{GC}$ values, 1000 replicates, cut $=1$ (tree 0) - Symmetric Resampling ( $\mathrm{P}=33$ )

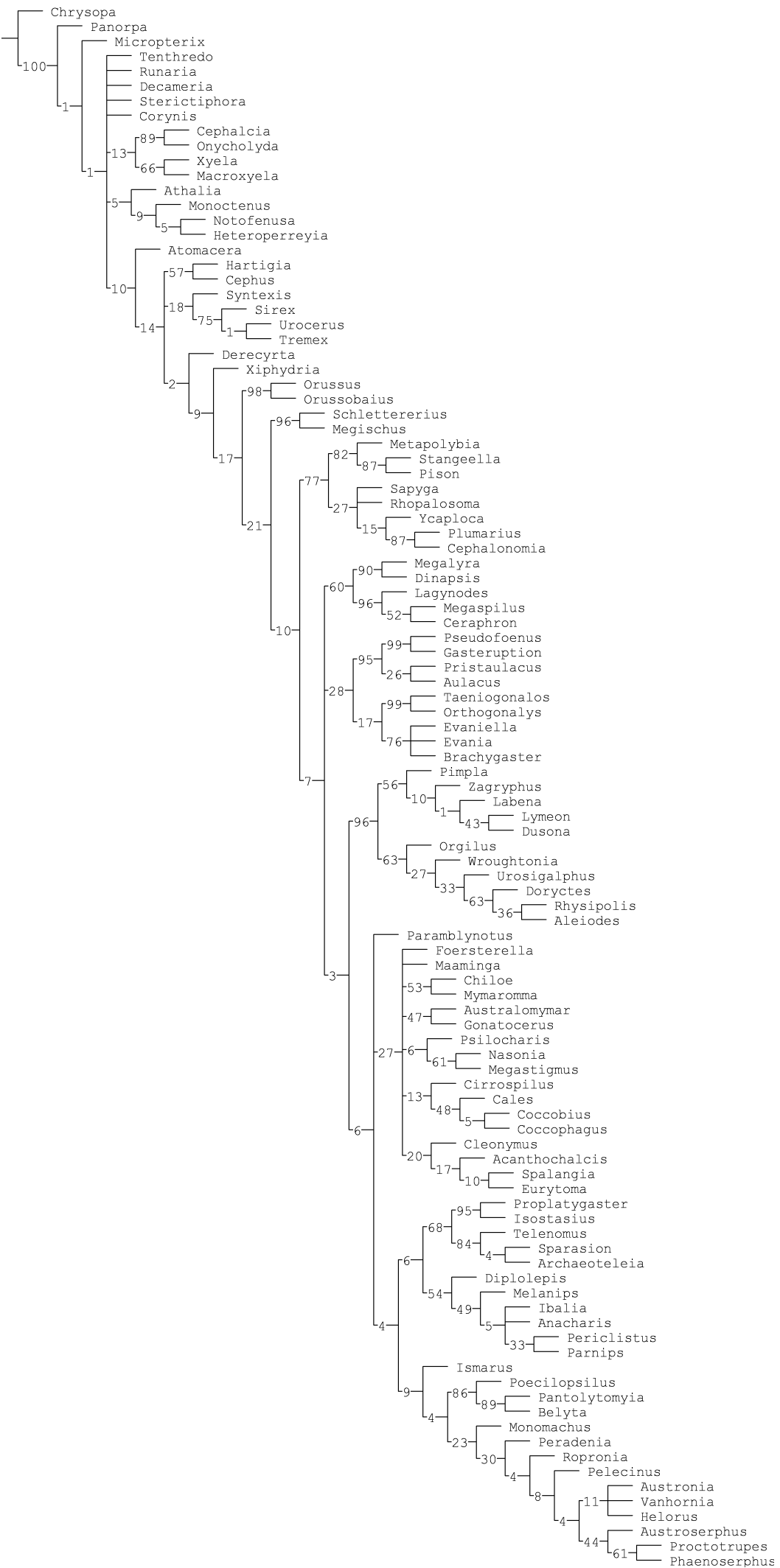

Fig. 5. Morphology support. 


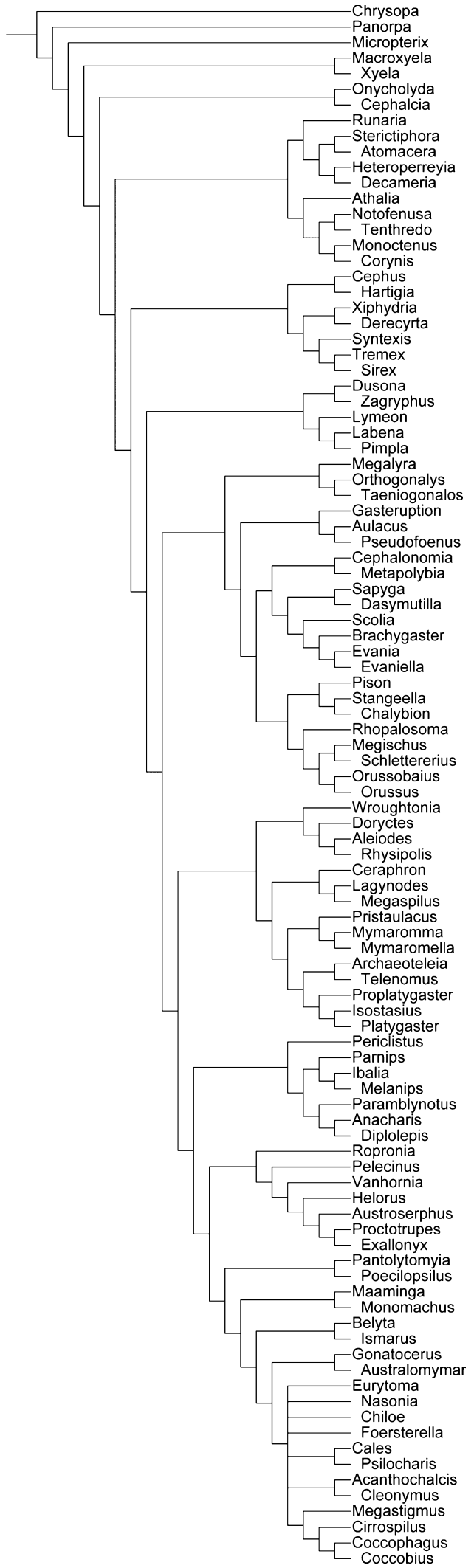

Fig. 6. Combined genes consensus, based on two trees of length $24645, \mathrm{CI}=0.21, \mathrm{RI}=0.37$.

$$
\begin{aligned}
& \text { Tenthredinoidea }+ \text { Cephoidea }+ \text { Siricoidea }+ \text { Xiphy- } \\
& \text { drioidea }+ \text { Orussoidea }+ \text { Apocrita }
\end{aligned}
$$

History: Not proposed in any recent morphological analyses. Present in some of Vilhelmsen et al.'s (2010) weighted analyses, but also contradicted in some.

Total-evidence: Present with RS $=18$.

Morphology: Neither supported nor contradicted in the morphology-only tree in which Tenthredinoidea is not monophyletic. When Tenthredinoidea is placed basal to Pamphilioidea on the morphology-only tree, the increase in length is only one step, suggesting rather equivocal morphological support for the two hypotheses. Monophyly of the entire assemblage is supported on the total-evidence tree by the following character states with little homoplasy as well as by the highly homoplastic characters 217 and 244.

287: lateral mesopleuro-postoccipital muscle absent.

293: profurco-protrochanteral muscle absent.

305: intersegmental membrane-mesobasalar muscle absent.

347: subcostal vein of forewing absent as a longitudinal vein.

353: subcostal vein of hind wing absent.

Genes: Present in the EF- $1 \alpha$ symmetric-resampling tree with $\mathrm{RS}=29$. Present in the all-genes consensus tree without support.

Alternatives: Pamphilioidea, as sister group to Cephoidea + Siricoidea + Xiphydrioidea + Orussoidea + Apocrita, occurs in our COI support tree with RS $=49$, the $18 \mathrm{~S}$ results with $\mathrm{RS}=21$, and the $28 \mathrm{~S}$ results with $\mathrm{RS}=79$. This is the relationship most often recovered in previous morphological analyses (Rasnitsyn, 1988; Ronquist et al., 1999; Vilhelmsen, 2001) and the molecular analyses (Heraty et al., 2011). Schulmeister et al. (2002) proposed the unique hypothesis of a sister group relationship between Pamphilioidea and Tenthredinoidea.

Conclusions: The two competing candidates for sister group to (Cephoidea + Siricoidea + Xiphydrioidea + Orussoidea + Apocrita), i.e., Pamphilioidea and Tenthredinoidea, are almost equally supported by our data.

Unicalcarida $=$ Cephoidea + Siricoidea + Xiphydrioidea + Orussoidea + Apocrita

History: This is a frequently suggested relationship supported by morphological data (Rasnitsyn, 1988; Ronquist et al., 1999; Vilhelmsen, 2001). It was also present in the combined results of Schulmeister et al. (2002). It was not retrieved in any of the trees presented by Vilhelmsen et al. (2010). Monophyly of the clade was present in all results of Heraty et al. (2011).

Total-evidence: The entire clade is present with $\mathrm{RS}=99$. 


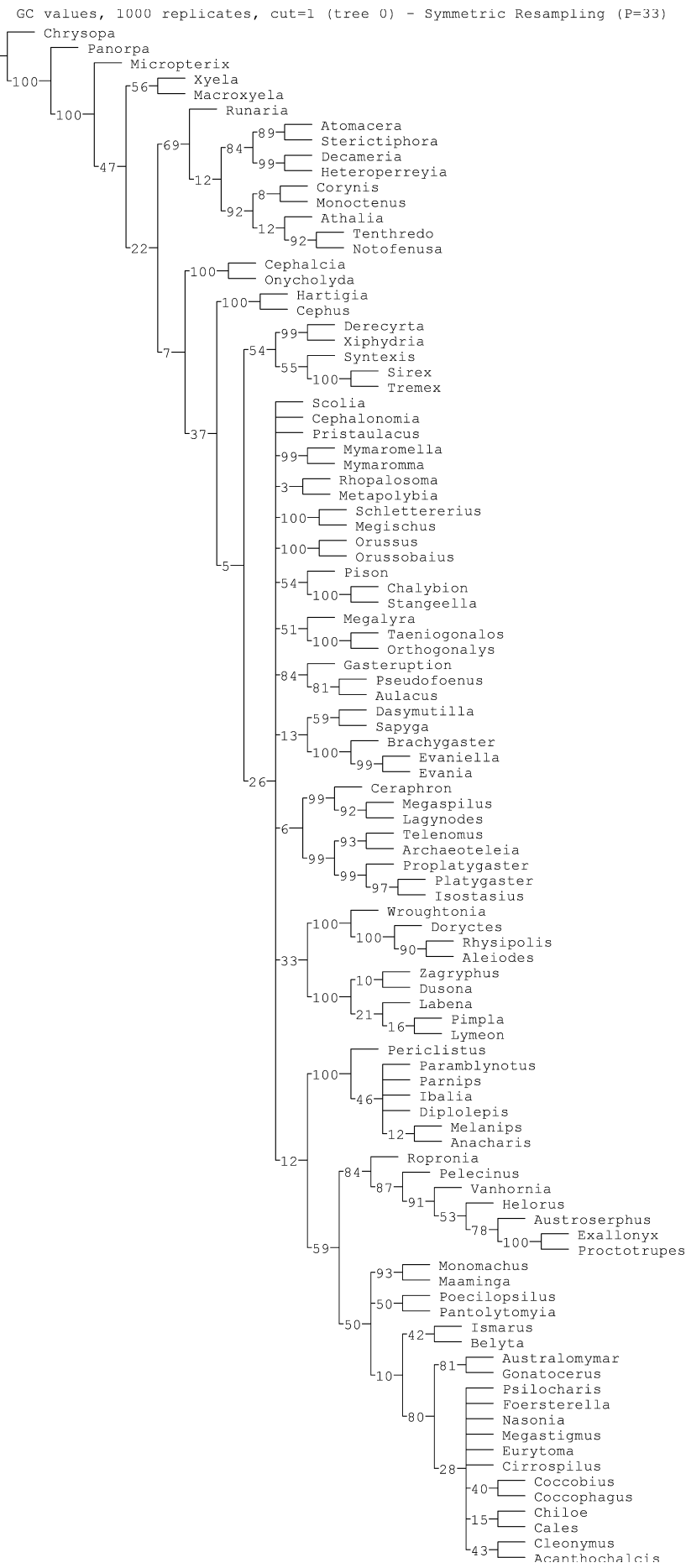

Fig. 7. Combined genes support.

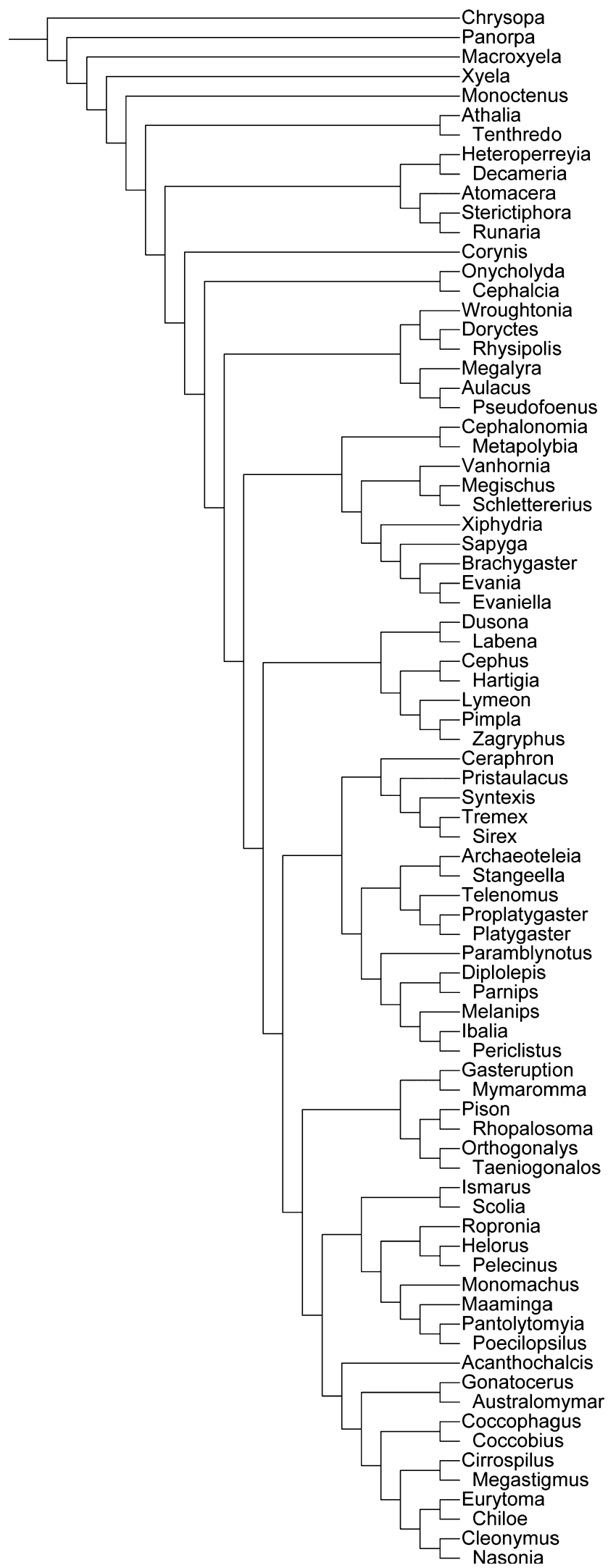

Fig. 8. COI single cladogram, length $7428, \mathrm{CI}=0.16, \mathrm{RI}=0.33$. 
GC values, 1000 replicates, cut=1 (tree 0) - Symmetric Resampling (P=33)

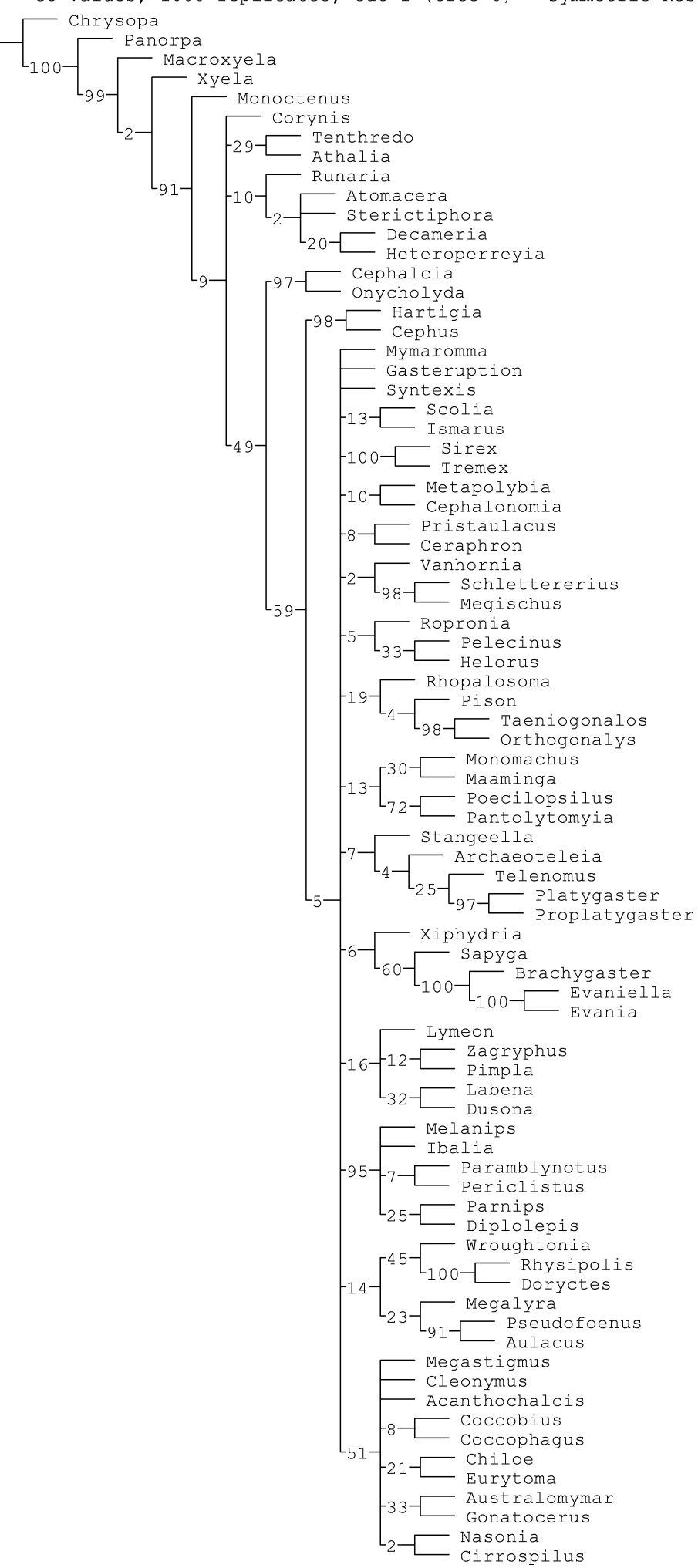

Fig. 9. COI support. 


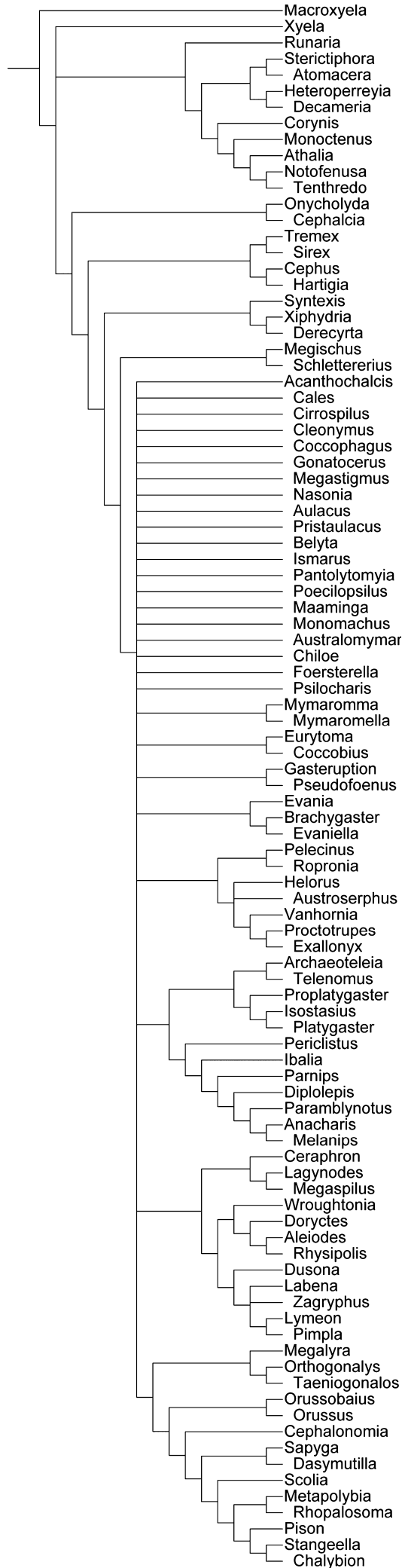

Fig. 10. $28 \mathrm{~S}$ consensus, based on 76 trees of length $7529, \mathrm{CI}=0.28$, $\mathrm{RI}=0.45$. Outgroups were deleted and Hymenoptera were re-rooted on Macroxyela (see text).

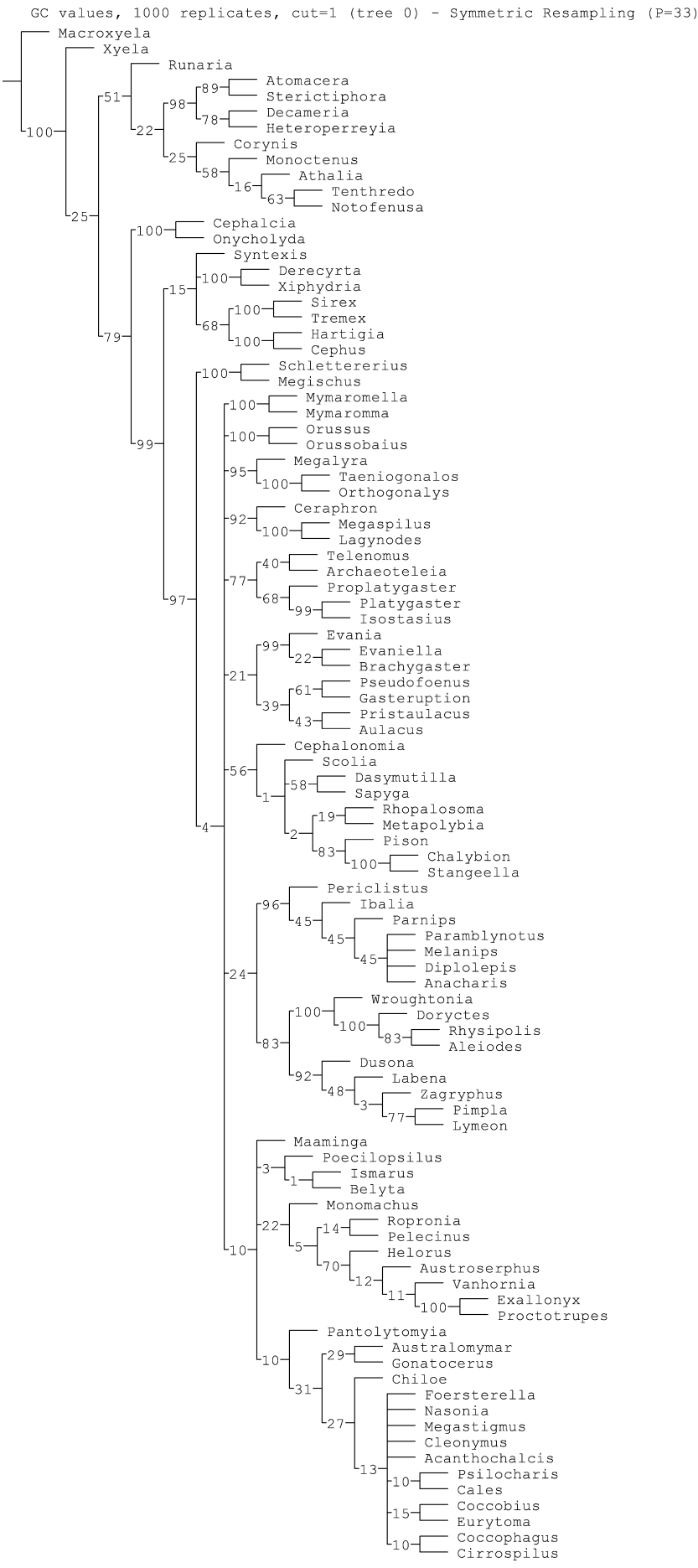

Fig. 11. 28S support. 
Morphology: Not present but not contradicted in morphology-only consensus tree and present in the symmetric-resampling morphology-only tree with $\mathrm{RS}=14$. Numerous synapomorphies support this relationship in the total-evidence tree. These are described by Vilhelmsen et al. (2010) except for the following.

27: distal epipharyngeal wall continuously sclerotized with the labrum.

359: veins $\mathrm{R}$ and $\mathrm{C}$ of hind wing fused in the area posterior to distal hamuli.

Genes: Present in the all-genes consensus tree with $\mathrm{RS}=37$. Present in the COI, 28S, and $18 \mathrm{~S}$ trees with relative-support values of 59,99 , and 75 respectively.

Alternatives: None.

Conclusions: Strongly supported by molecular and morphological data, and by previous morphological studies.

\section{Siricoidea s.l. including Anaxyelidae}

History: Siricoidea s. str., i.e., excluding Anaxyelidae, has long been thought to be a monophyletic group. The critical question is whether or not Anaxyelidae should be included. Most morphological studies have placed Anaxyelidae basal to Siricoidea forming a grade (Rasnitsyn, 1988; Ronquist et al., 1999). Vilhelmsen et al. (2010) recovered the clade Anaxyelidae + Siricidae in a few of their results. The first molecular support is in Schulmeister et al. (2002). Heraty et al. (2011) recovered Anaxyelidae as sister to Siricidae with strong support in all analyses.

Total-evidence: Anaxyelidae is present as the sister group to the remaining Siricoidea with a RS value for the entire clade of 95.

Morphology: Present in the morphology-only symmetric-resampling tree with $\mathrm{RS}=22$. There are five morphological character states with little or no homoplasy supporting this relationship in the total-evidence tree.

57: labial palpus reduced to three segments.

164: tegulum concealed by dorsolateral corner of pronotum.

217: metapleural apodeme absent or weakly developed.

244: dense brush of setae present on hind tibia.

363: mesotibia with one apical spur.

Genes: Present in the all-genes consensus tree with RS of 55. Present in the EF- $1 \alpha$ support tree with $\mathrm{RS}=20$. Not contradicted by other genes except $28 \mathrm{~S}$ in which the improbable relationship of Siricidae + Cephidae has $\mathrm{RS}=68$.

Alternatives: None from our analyses. The possibility of Anaxyelidae and Siricidae forming a grade is only weakly suggested by previous morphological analyses.

Conclusions: Strongly supported with evidence from both molecular and morphological data.

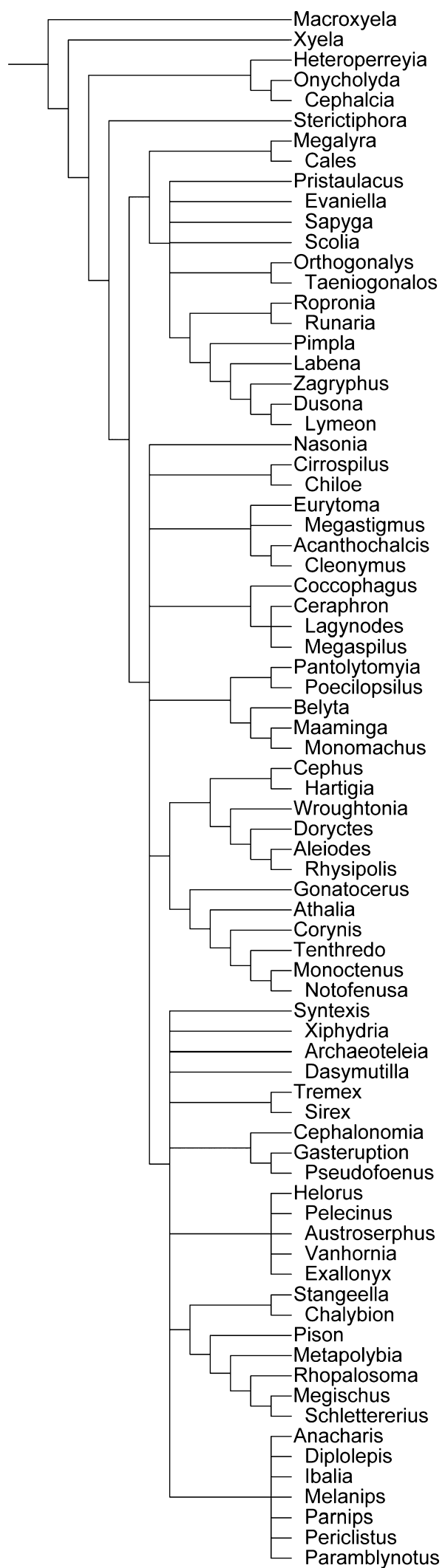

Fig. 12. EF- $1 \alpha$ consensus, based on 34 trees of length 6329, $\mathrm{CI}=0.14$, RI $=0.36$. 
GC values, 1000 replicates, cut=1 (tree 0) - Symmetric Resampling (P=33)

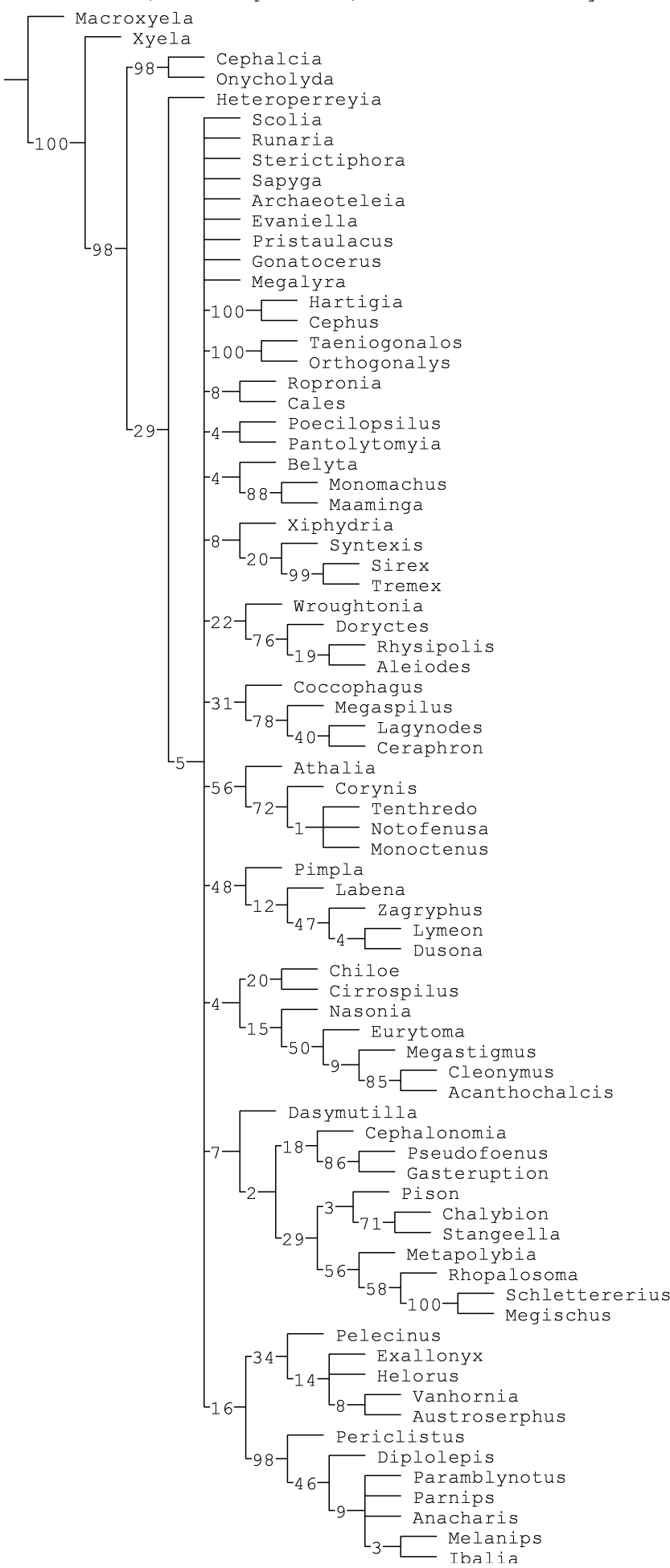

Fig. 13. EF-1 $\alpha$ support. 


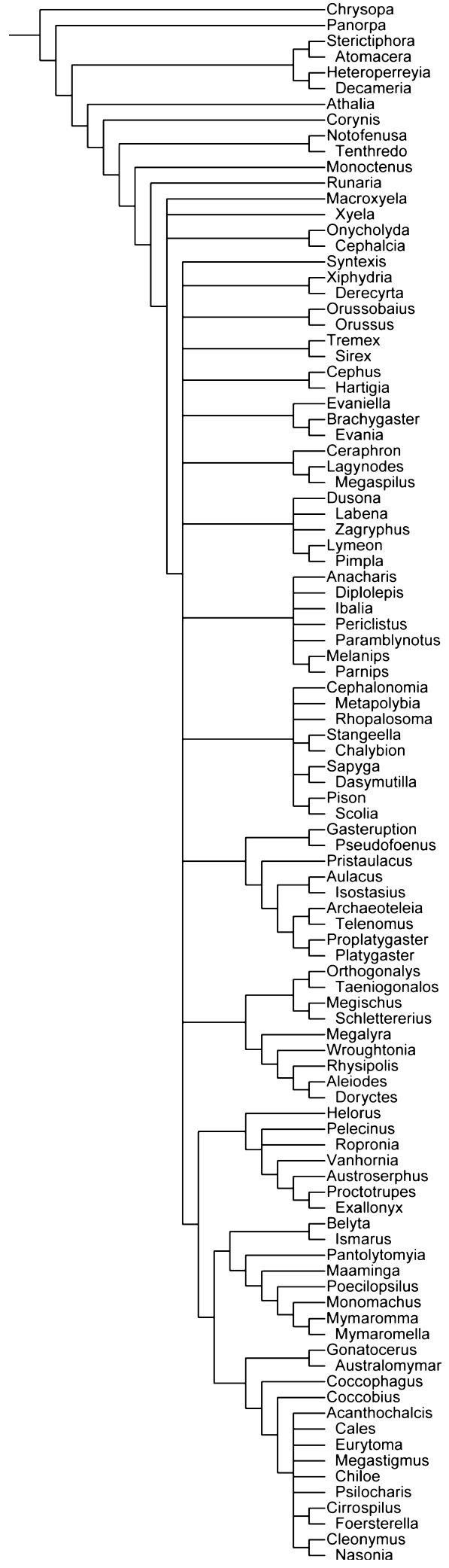

Fig. 14. 18S consensus, based on 460 trees of length 2054, CI $=0.36$, $\mathrm{RI}=0.54$. Micropterix (Lepidoptera), which nested within Apocrita, was deleted.

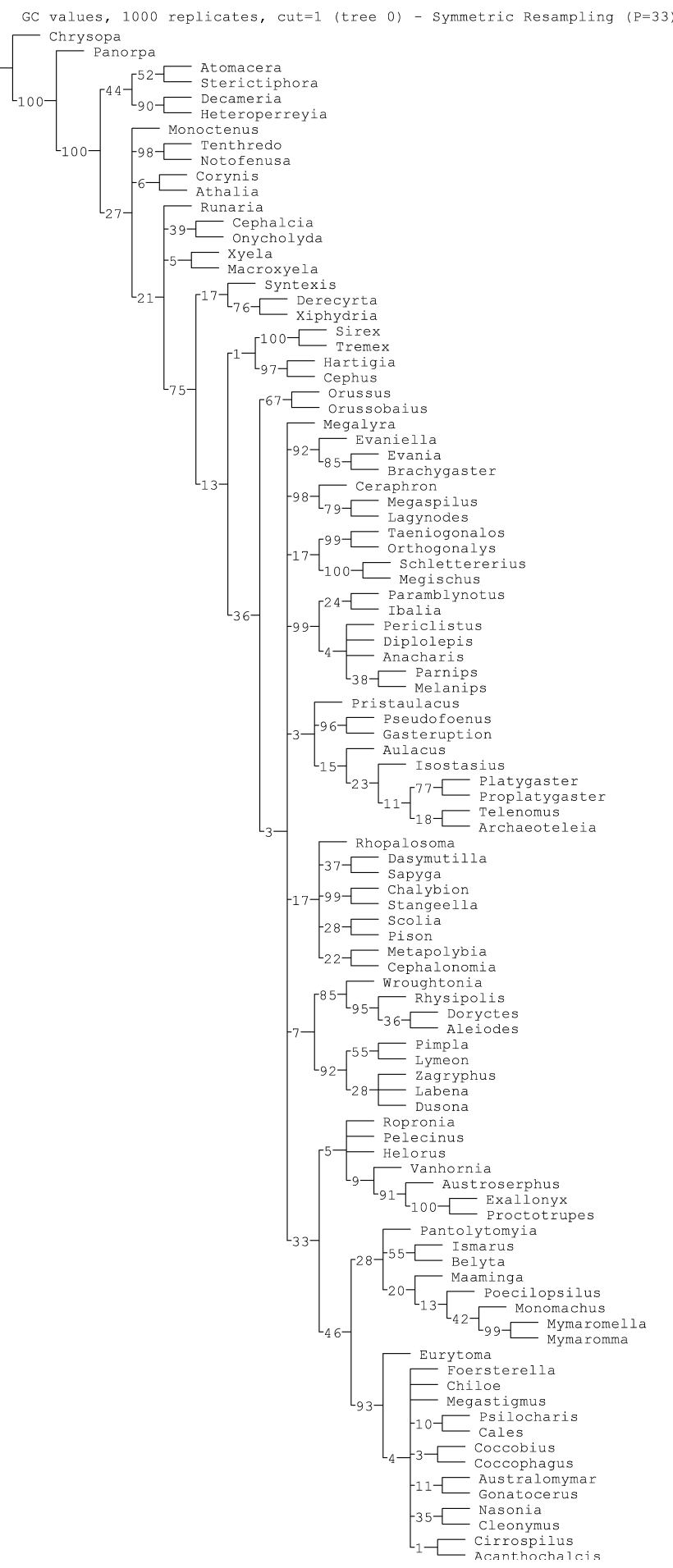

Fig. 15. 18S support. 
Siricoidea s.l + Xiphydrioidea + Orussoidea + Apocrita

History: Siricoidea has been thought of as the sister group, or a grade immediately basal to, Xiphydrioidea + (Orussoidea + Apocrita) (Rasnitsyn, 1988; Ronquist et al., 1999; Vilhelmsen et al., 2010).

Total-evidence: Present with RS $=55$. Since this is a much higher value than that of the all-genes tree, morphology must also be making a contribution.

Morphology: Not present in the morphology-only trees. Two morphological synapomorphies support the relationship in the total-evidence tree.

24: labrum thin and cylindrical.

392: loss of labial silk production, with a reversal in Apocrita.

Genes: Present in the all-genes tree with RS of 5, present in the COI consensus tree with RS of 5.

Alternatives: An alternative that has received some attention is Cephoidea + Xiphydrioidea + Orussoidea + Apocrita. This relationship is not supported in any of our results but was present in all of the likelihoodbased results of Heraty et al. (2011), and was also frequently retrieved by Vilhelmsen et al. (2010).

Conclusions: Moderately supported by a combination of genes and morphology.

\section{Xiphydrioidea + Orussoidea + Apocrita}

History: This is a long standing relationship included in Rasnitsyn's (1988) treatment and recovered in the cladistic analysis of his data by Ronquist et al. (1999). The parsimony analysis of the secondary structure alignment of Heraty et al. (2011) also recovered this group.

Total-evidence: Present with RS $=15$.

Morphology: The two exemplars of Xiphydrioidea appear as a grade basal to Orussoidea + Apocrita but there is little doubt of their monophyly, which the allgenes tree supports. Present in the morphology-only tree with $\mathrm{RS}=2$. Sixteen morphological synapomorphies support this relationship in the total-evidence tree, i.e., $11,56,130,133,134,135,138,159,160,161,171,201$, $207,215,239,240$. These are discussed by Vilhelmsen et al. (2010) except as follows:

11: occipital sulcus and ridge absent. This character state is uniquely derived on the total-evidence consensus tree.

56: base of paraglossa spinose, with a reversal to setose or bare in the Proctotrupomorpha.

Genes: There is no support from any of the genes employed in this study.

Alternatives: Our all-genes tree and many of the individual gene trees in our study suggest that Xiphydrioidea is the sister group to some or all of the Siricoidea. This relationship is recovered in the all-genes consensus tree with $\mathrm{RS}=54$. The same relationship was recovered in the Bayesian analysis of Heraty et al.
(2011) with a posterior probability of 0.99 , so clearly there is strong molecular signal.

Conclusions: Morphology strongly supports this relationship and the molecular data generally contradict it; as a result, overall support is rather weak.

\section{Orussoidea + Apocrita}

History: Orussoidea has long been thought to be the sister group to the Apocrita based on morphological and behavioral evidence (Rasnitsyn, 1980). Most recently Vilhelmsen et al. (2010) retrieved this relationship with strong support in all analyses. The clade is recovered in all of the molecular results of Heraty et al. (2011).

Total-evidence: Present with RS $=100$.

Morphology: Present in the morphology-only tree with $\mathrm{RS}=17$. In the total-evidence tree support comes from 44 characters, including the following 14 characters with uniquely derived states: 21(1), 55(3), 98(1), 122(1), 152(1), 180(1), 194(1), 202(1), 206(1), 209(1), 298(0), 302(0), 320(0), and 391(1). See Vilhelmsen (2001) and Vilhelmsen et al. (2010) for detailed lists.

Genes: The group is present in the all-genes consensus tree with RS $=26$ and though not present in the $18 \mathrm{~S}$ consensus tree it is in the $18 \mathrm{~S}$ support tree with $\mathrm{RS}=36$.

Alternatives: None.

Conclusions: Strongly supported by behavioral, morphological, and sequence data.

\section{Apocrita}

History: A long-recognized group with an obvious synapomorphy in the constriction between abdominal segments one and two and the development of the propodeum. This group was supported in some of the secondary-structure results from Heraty et al. (2011).

Total-evidence: Strongly supported with RS $=98$.

Morphology: The evidence from morphological characters is strong with 24 synapomorphies in the total-evidence tree, including the uniquely derived states for the following characters 38(1), 209(2), 262(2), 281(0), 291(0), 297(0), 300(0), 316(0), 317(0), 322(0), 339(0), 349(1). Apocrita does not occur in the morphology-only consensus tree but in the morphology-only support tree it has $\mathrm{RS}=21$. Extensive lists of synapomorphies for Apocrita can be found in Vilhelmsen (2001) and Vilhelmsen et al. (2010).

Genes: Although contradicted in the all-genes tree, Apocrita is present in the $18 \mathrm{~S}$ support tree with $\mathrm{RS}=3$.

Alternatives: None.

Conclusions: Strongly supported by morphological data and weakly corroborated by $18 \mathrm{~S}$ data. 


\section{All Apocrita except Stephanoidea}

History: Vilhelmsen et al. (2010) recently proposed this relationship based on mesosomal characters; it was also proposed by Rasnitsyn (1980).

Total-evidence: Present with RS $=2$.

Morphology: Present with $\mathrm{RS}=10$. All Apocrita except Stephanoidea is supported by nine morphological character states, three of which $(116,143$ and 231) are uniquely derived.

116: procoxa constricted basally (Vilhelmsen et al., 2010, figs $42 \mathrm{~A}-\mathrm{C}$ ).

143: mesonotum, configuration of mesoscutellar carina; not reaching transscutal carina/articulation.

231: lateral metathoracic coxal articulation concealed in lateral view (Vilhelmsen et al., 2010, figs 57B-D) with a reversal in one aculeate and in Megalyroidea.

83: pronotum rigidly attached to mesopleuron.

85: prepectus absent (Vilhelmsen et al., 2010, figs 37F, $38 \mathrm{~B}$, D) with a reversal in Chalcidoidea. Due to the distance between these two superfamilies this is a convincing synapomorphy.

88: prepectus/pronotum dorsal inflection extending dorsal to anterior spiracle (Vilhelmsen et al., 2010, figs 37F, 38B, D).

156: median longitudinal carina of mesophragma absent or weakly developed (Vilhelmsen et al., 2010, figs $47 \mathrm{C}, \mathrm{F}$ ).

238: anterior metafurcal arm reduced (Vilhelmsen et al., 2010, figs 58B-D).

285: anterior spiracle occlusor muscle arising from the pronotum.

Genes: Not present in the $28 \mathrm{~S}$ consensus tree but present in the $28 \mathrm{~S}$ support tree with $\mathrm{RS}=4$ (ignoring the fact that this tree places Orussoidea within the Apocrita).

Alternatives: Stephanoidea + Trigonaloidea is present in the $18 \mathrm{~S}$ consensus tree with RS $=17$.

Conclusions: Moderately supported by morphological evidence and weakly corroborated by $28 \mathrm{~S}$ data.

\section{Megalyroidea + Ceraphronoidea + Trigonaloidea + Evanioidea + Aculeata}

History: This clade, except including Stephanoidea and sometimes Orussoidea, was recovered in Heraty et al. (2011).

Total-evidence: Present, but lacking RS.

Morphology: Not present in the morphology-only tree. Supported by three morphological synapomorphies in the total-evidence tree, i.e., 186, 218, 293.

186: medial mesocoxal articulation situated distally on medial surface of mesocoxa. This character state supports the monophyly of all members of this group with the exception of Aculeata in which the character state is reversed (Vilhelmsen et al., 2010, fig. 51A).
218: mesopleuron and metapleuron fused ventrally; also fused laterally in Ceraphronoidea.

293: profurco-protrochanteral muscle absent, convergent in Ichneumonoidea and Chalcidoidea.

Genes: Not present in any of the gene trees.

Alternatives: There are no strong alternatives. The concept of Evaniomorpha (Rasnitsyn, 1988), which excludes Aculeata and includes the remaining taxa (above) plus Stephanoidea, is not supported in any of our analyses or those of other recent molecular, morphological, or combined analyses. Some combination of these superfamilies may form a grade basal to the Proctotrupomorpha.

Conclusions: The placement of Trigonaloidea, Megalyroidea, and especially Ceraphronoidea are basically unknown, although our results suggest several interesting and unique hypotheses.

\section{Megalyroidea + Ceraphronoidea}

History: Vilhelmsen et al. (2010) proposed this relationship based on mesosomal characters. It is found in their strict consensus tree of unweighted data and in most of the weighted results.

Total-evidence: Present in the consensus tree with $\mathrm{RS}=11$.

Morphology: Present in the morphology-only support tree with $\mathrm{RS}=60$. In the total-evidence tree the relationship is supported by a uniquely derived state of character 327(1), the anterior metapleuron-metabasalare muscle originating from the wall of the fused mesometapectus. Thirteen homoplastic character states also support this relationship, i.e., 4(0), 72(1), 81(1), 82 (2), $84(1), 113(0), 129(0), 131(2), 136(1), 155(0), 172(1)$, 295(1), and 300(1). Those worthy of mention are:

4: antennal insertions below or level with lower margin of eyes.

81: posterolateral margin of pronotum straight. (Vilhelmsen et al., 2010, fig. 37C)

82: spiracle of pronotum surrounded by cuticle (perhaps not independent from 80) (Vilhelmsen et al., 2010, fig. 37C).

84: lateroventral corners of pronotum with medial inflections abutting mesopleuron (Vilhelmsen et al., 2010, fig. 36E).

113: anterior apodemes of profurca absent or weakly developed (Vilhelmsen et al., 2010, cf. fig. 40D).

129: median mesoscutal sulcus well developed internally and externally (Vilhelmsen et al., 2010, figs 44C, E).

295: dorsal mesofurco-profurcal muscle present (Vilhelmsen et al., 2010; fig. 4B).

300: anterior mesonoto-mesotrochanteral muscle present (Vilhelmsen et al., 2010, figs 17A, E).

Genes: Not present in any gene trees. 
Alternatives: The relationship Ceraphronoidea + Megalyroidea is supported by morphological evidence only. The relationship Megalyroidea + Trigonaloidea is present in the all-genes consensus tree with RS $=51$. It is also present in the $28 \mathrm{~S}$ consensus tree with RS of 95 . This is interesting because no dubious or obviously false relationship has a support value this high in any of the individual gene trees. In the $28 \mathrm{~S}$ tree, typical false positives are below 20 , with one in the 30 s and one with a value of 60 . The latter is the highest false positive value and unites Sapyga, an aculeate, with Aulacidae. Heraty et al. (2011) also recovered a sister group relationship between Megalyroidea + Trigonaloidea with a posterior probability of 0.97 . Although the relationship Megalyroidea + Trigonaloidea does not occur in our total-evidence tree, it should be considered a likely alternative worthy of more investigation with denser sampling and/or more genetic markers.

Conclusions: Monophyly of the clade is only weakly supported due to conflict between molecular and morphological data.

\section{Trigonaloidea + Aculeata + Evanioidea}

History: This is a novel, but weakly supported, proposal.

Total-evidence: Present but lacking support.

Morphology: Not present in the morphology-only tree. In the total-evidence tree there is support from numerous characters, however none is uniquely derived.

215: metapleuron lacking dorsal longitudinal ridge (Vilhelmsen et al., 2010, cf. fig. 55A).

239: lateral metafurcal arm fused with metapleural apodeme (Vilhelmsen et al., 2010; fig. 3A).

290: mesofurco-propleural arm muscle present (Vilhelmsen et al., 2010; fig. 11D).

292: origin of median profurcal-procoxal muscle from the posteroventral part of the profurca (Vilhelmsen et al., 2010; fig. 8C).

329: posterior metapleuro-metabasalare muscle present (Vilhelmsen et al., 2010; figs 3B, 28G).

369: mesotibial apical sensillum absent.

392: labial silk production from salivary gland secretions. (Also found in basal sawflies and convergently in Ichneumonoidea.)

Genes: Not present in any of the gene trees.

Alternatives: The relationship Megalyroidea + Trigonaloidea is present in the all-genes tree with RS $=51$, and this relationship is also present in the $28 \mathrm{~S}$ consensus tree with RS $=95$. (See previous section.)

Conclusions: Monophyly is weakly supported.

Evanioidea + Aculeata

History: This is a novel proposal.

Total-evidence: Present with RS $=15$.
Morphology: Not present in the morphology-only tree. Three morphological character states support the relationship in the total-evidence tree. They are all moderately homoplastic.

252: metaphragma-metapleural apodeme fused (Vilhelmsen et al., 2010, fig. 58E).

320: median metapleuro-metanotal muscle present (Vilhelmsen et al., 2010; figs 12B, 28F, G).

373: tibial comb of midleg absent.

Genes: Present in the all-genes tree but lacking support, with the caveat that Orussoidea is nested within Aculeata. Not present in any of the individual gene analyses.

Alternatives: There are no strong alternatives to this placement. Part of the difficulty of assessing the support for this relationship lies in the placement of the Trigonaloidea, which jumps around near these two taxa, as well as the lack of monophyly of the Aculeata in many of the single gene trees.

Conclusions: The clade Evanioidea + Aculeata is weakly to moderately supported.

Aculeata

History: This is a longstanding clade that until recently was considered a suborder. Few synapomorphies other than the lack of an ovipositor that functions as such have been proposed.

Total-evidence: Present with RS $=32$.

Morphology: Present in the morphology-only consensus tree with a support value of 76 . Seventeen morphological character states support this clade in the totalevidence tree. Of these, the following five are uniquely derived states.

337: metasterno-second abdominal sterna muscle present.

383: egg exit at base of ovipositor.

385: furcula of ovipositor present.

386: ovipositor sheaths divided into two segments.

388: second valvifer subdivided, pars articularis present.

Genes: Present in the all-genes consensus tree but lacking support. Present in the $28 \mathrm{~S}$ and $18 \mathrm{~S}$ consensus trees with RS values of 56 and 17 respectively.

Alternatives: None.

Conclusions: Well-supported but showing significant homoplasy in both morphological and molecular characters.

\section{Evanioidea}

History: This is a long-standing superfamily that has rested on one putative synapomorphy, the attachment of the metasoma high above the hind coxal cavities, which is also found in scattered groups of Ichneumonoidea and Chalcidoidea, e.g. Cenocoeliinae (Braconidae). The Evanioidea was recovered with high support by Dowton et al. (1997) based on 16S rRNA. It was also recovered in 
many of the analyses of Vilhelmsen et al. (2010). The clade was strongly supported in all of the Bayesian analyses (PP 85-92) of Heraty et al. (2011), present but without bootstrap support in the likelihood analyses, and present in the parsimony analysis of the eye alignment with third codon positions excluded; there were no conflicting arrangements in the remainder.

Total-evidence: Present with RS $=45$.

Morphology: Not present in the morphology-only consensus tree or support tree. One uniquely derived character state supports the clade, 264(2), the high position of the propodeal foramen.

Five homoplastic character states offer additional, albeit weak support.

59: subapical sensillae present on basal labial palpomere, (very homoplastic).

69: pronotum reduced anteriorly (Vilhelmsen et al., 2010, figs 37B, C).

101: propleural arms horizontal, extending medially posterior to profurca (Vilhelmsen et al., 2010, fig. 41D).

192: anterior projection on bridge of mesofurca absent (Vilhelmsen et al., 2010, cf. fig. 52D).

263: sclerite between hind coxae and metasomal foramen (Vilhelmsen et al., 2010, figs 60C, D).

Genes: Present only in the $28 \mathrm{~S}$ consensus tree with a support value of 21 .

Alternatives: The clade Trigonaloidea + Evanioidea is present in the morphology-only support tree with $\mathrm{RS}=17$. This relationship was also retrieved in some of the analyses of Vilhelmsen et al. (2010). However there is no molecular evidence to support it.

Conclusions: Monophyly of Evanioidea is strongly supported by molecular data in this analysis (28S), as well as that of Dowton et al. (1997) employing 16S, and by molecular data under multiple parameters, including secondary-structure alignment, in Heraty et al. (2011).

\section{Ichneumonoidea + Proctotrupomorpha}

History: This relationship was first suggested by Johnson (1988). It was present in several of the trees produced by the ML analyses of Dowton and Austin (2001) but not included in their consensus cladogram. The relationship was supported by the most weakly weighted of the analyses $(\mathrm{k}=25)$ of Vilhelmsen et al. (2010). The clade was supported in the Bayesian analysis of Heraty et al. (2011), with a posterior probability of 0.92 , and present with variable support under multiple parameter sets in their analyses including those employing secondary-structure alignment.

Total-evidence: Present in the consensus tree with $\mathrm{RS}=18$.

Morphology: Present in the morphology-only support tree with $\mathrm{RS}=3$. Ten morphological synapomorphies support the clade in the total-evidence tree, none of which is uniquely derived, i.e., 5, 19, 41, 82, 170, 195,
222, 226, 248, 263. Those with limited homoplasy include the following.

19: occipital carina reaching hypostome ventrally.

41: teeth on left mandible reduced to three.

195: proximal part of mesocoxa very reduced (Vilhelmsen et al., 2010; figs 53B, D), only convergent in some Aculeata; see also Johnson (1988).

Genes: Present in the $28 \mathrm{~S}$ consensus tree but without support.

Alternatives: A sister group relationship between Aculeata and Ichneumonoidea was suggested by Rasnitsyn (1988) based on the exclusive presence of ovipositor valvilli in both taxa and the presence of condyles on the propodeum for the mesosomal-metasomal articulation. However this relationship was not recovered in the cladistic analysis of his data by Ronquist et al. (1999). Vilhelmsen et al. (2010) demonstrated that the presence of the propodeal condyles is widespread in other apocritan taxa. No support for the clade Aculeata + Ichneumonoidea is found in our analyses or in that of Heraty et al. (2011) under any parameter settings; however Vilhelmsen et al. (2010) recovered this relationship in some of their weighted analyses and Dowton and Austin (1994) recovered the same using $16 \mathrm{~S}$ data.

Conclusions: Monophyly of Ichneumonoidea + Proctotrupomorpha is well-supported. Part of the strength of this relationship is the lack of a viable alternative as the Aculeata + Ichneumonoidea relationship is not well supported by any data other that the presence of valvilli. Other strengths include the presence of the signal in both the molecular and morphological data.

\section{Proctotrupomorpha $=$ Platygastroidea + Cynipoidea + Proctotrupoidea s. str. + Diaprioidea + Mymaromma- toidea + Chalcidoidea}

History: First proposed by Rasnitsyn (1988), but not supported in the cladistic analyses of his data (Ronquist et al., 1999). The clade was recovered by most of the analyses of Dowton and Austin (2001), as well as the Bayesian analysis of Castro and Dowton (2006) with a posterior probability of 0.67 , and the parsimony analysis of $16 \mathrm{~S}$ data by Dowton et al. (1997). The latter analysis contained few apocritans outside of the Proctotrupomorpha so the test of monophyly was limited. It was supported in all Bayesian and likelihood analyses of Heraty et al. (2011). It was also present in the unweighted morphological parsimony analysis of Vilhelmsen et al. (2010), as well as in some of their weighted analyses. Heraty et al. (2011) recovered the clade with strong support (PP 92-100; BS 72-99) in all of their statistical analyses, and in one of their parsimony analyses.

Total-evidence: Present with RS $=60$.

Morphology: Not present in the morphology-only consensus tree but present in the support tree with 
$\mathrm{RS}=6$. One uniquely derived character state in the total-evidence tree is 344: cubital vein of forewing not bent sharply towards the posterior margin of the wing apical to the $1 \mathrm{~m}-\mathrm{cu}$ crossvein.

There are 13 homoplastic character states supporting the clade. Those worthy of mention are:

56: paraglossal basal setation setose or bare (as opposed to spinose).

57: number of labial palpomeres reduced to 3 as opposed to 4 which is the number found as ground plan to almost all other apocritan superfamilies.

61: number of maxillary palpomeres reduced to 5 as opposed to 6 which is the number found in almost all other apocritans (likely not entirely independent of the previous character).

Genes: Not present in the all-genes support tree, only because Mymarommatoidea are included in a large polytomy directly basal to the remaining Proctotrupomorpha; the latter has $\mathrm{RS}=12$. Not present in any of the individual gene analyses. This is often due to the inclusion of ceraphronoids and/or the exclusion of Mymarommatoidea or Cynipoidea.

Alternatives: The $28 \mathrm{~S}$ support tree includes the clade Ichneumonoidea + Cynipoidea with RS of 24. This is not supported by any published evidence or by any other genes in our analyses.

Conclusions: Monophyly of Proctotrupomorpha (sensu Rasnitsyn, 1988) is strongly supported by the collective signal of genes and morphology.

\section{Platygastroidea + Cynipoidea}

History: This relationship appears in several of the trees based on parsimony analyses of the molecular data of Dowton and Austin (2001), but it was not included in their preferred results. The relationship was further supported in the Bayesian analysis of Castro and Dowton (2006), although with weak support, posterior probability of 0.37 . Platygastroidea + Cynipoidea was present in the parsimony analyses of Heraty et al. (2011), with weak support.

Total-evidence: Present with RS $=42$.

Morphology: Although the cynipoid Paramblynotus is an outlier, the remaining Cynipoidea + Platygastroidea are present as a clade in the morphology-only support tree with $\mathrm{RS}=6$. Eight homoplastic, morphological synapomorphies support the clade in the total-evidence tree, 32(1), 45(1), 68(1), 184(2), 185(0), 220(0), 293(0), and $345(1)$, of which the following are worthy of mention.

68: stipes with prominent sensillum. Convergent occurrences in Monomachus and Ceraphronoidea.

184: mesocoxal foramina closed dorsally, surrounded by continuous mesopleural cuticle (Vilhelmsen et al., 2010, fig. 51B).
185: median mesocoxal articulation absent (Vilhelmsen et al., 2010, fig. 51B).

293: profurco-protrochanteral muscle absent, also absent in all Chalcidoidea.

345: forewing costal vein absent or not complete as a tubular vein, convergent in Chalcidoidea + Mymarommatoidea.

Genes: Present in the COI and 28S consensus trees but without support.

Alternatives: The clade Proctotrupoidea + Cynipoidea is not present in the EF- $1 \alpha$ consensus tree but is present in the support tree, with the exception of the proctotrupoid outlier Vanhornia, with $\mathrm{RS}=16$. No other individual gene supports this relationship.

Conclusions: The clade Platygastroidea + Cynipoidea receives moderately strong molecular support and is weakly contradicted by morphological data. The relationship is corroborated by the molecular data of Dowton and Austin (2001), Castro and Dowton (2006), and the Bayesian analysis of Heraty et al. (2011). The relationship has a strong RS value of 42 in the total-evidence tree. To put perspective on this number, the relative-support values of well corroborated clades such as Aculeata and Braconidae are values of 38 and 43, respectively.

\section{Proctotrupoidea + Diaprioidea + Mymarommatoidea + Chalcidoidea}

History: Present in Heraty et al. (2011) in most analyses with strong support. The same clade was recovered by Castro and Dowton (2006), but they did not have Mymarommatoidea in their analyses.

Total-evidence: Present with RS $=53$.

Morphology: Two morphological synapomorphies are present in the total-evidence tree, i.e.,

153(0): mesophragma character state (wildly homoplastic).

270: petiole (first metasomal segment) posteriorly narrow, approximately same width as anterior foramen (Vilhelmsen et al., 2010, figs 66D-F). Convergent only in Ibalia (Cynipoidea) among Proctotrupomorpha.

Genes: Present in the $18 \mathrm{~S}$ consensus tree with $\mathrm{RS}=33$. Not present in the all-genes consensus tree, however with the exception of Mymarommatoidea it occurs in the support tree with RS $=59$.

Alternatives: The morphology-only support tree includes Cynipoidea + Platygastroidea in this clade as the sister group to a paraphyletic Diaprioidea and Chalcidoidea, albeit with weak support, $\mathrm{RS}=4$. Castro and Dowton (2006) placed Proctotrupoidea as a paraphyletic grade basal to (Platygastroidea + Cynipoidea) in two of their hypotheses.

Conclusions: Monophyly of clade is strongly supported by multiple molecular data sources; morphological data are equivocal. 


\section{Proctotrupoidea s. str.}

History: The concept of Proctotrupoidea has changed considerably over the past few decades. It has been a "dumping ground" for unplaced apocritans since its inception and once included taxa such as Bethyloidea, Evanioidea, and Mymaridae (Chalcidoidea). Masner (1956) proposed excluding the taxa now known as Ceraphronoidea and Platygastroidea, and Sharkey (2007) excluded the Diaprioidea to arrive at what is termed here Proctotrupoidea s. str. The clade is present in almost all of the analyses of Heraty et al. (2011) with strong support.

Total-evidence: Present with RS $=70$.

Morphology: Absent in the morphology consensus tree. Present in the support tree with RS $=31$, but as a derived element within Diaprioidea. Supported by 12 synapomorphies in the total-evidence tree, i.e., 13(1), 15(1), 64(1), 128(1), 139(1), 143(1), 148(1), 216(0), 314(1), 357(1), 358(0) and 362(1), of which the following are worthy of mention.

13: posterior tentorial pits ventral to occipital foramen, with little homoplasy.

128: mesonotum, anterior mesoscutal sulcus configuration with distinct ventral extension onto prophragma anteromedially (Vilhelmsen et al., 2010, fig. 43B), convergent in Ismarus and two of the six platygastroids.

314: lateral mesofurcal mesotrochanteral muscle present, convergent in some platygastroids (Vilhelmsen et al., 2010, figs 21B, C).

357: costal margin of hind wing broadly curved, convergent only in one cynipoid.

358: hind wing with a costal trough extending from base to hamuli, convergent in Monomachus.

362: presence of sclerotized glabrous plate posterior to hamuli. Convergent in Cynipoidea and Monomachus.

Genes: Present in the all-genes tree with $\mathrm{RS}=84$. Only three exemplars are represented in the COI data set, nonetheless Proctotrupoidea s. str. is present in the consensus tree although without relative support. Present in both the $18 \mathrm{~S}$ and $28 \mathrm{~S}$ consensus trees, with $\mathrm{RS}=5$ in each case.

Alternatives: No strong alternatives. See Diaprioidea.

Conclusions: Monophyly of Proctotrupoidea s. str. is highly supported from multiple data sources.

\section{Diaprioidea + Mymarommatoidea + Chalcidoidea}

History: This clade was supported in both statistical and parsimony analyses by Heraty et al. (2011), but with strong support only in the Bayesian analyses (PP $=94$ 100).

Total-evidence: Present with RS $=6$.

Morphology: Not present in the morphology-only trees. States of characters 34, 130 and 361 support monophyly in the total-evidence tree.
34: labral setae restricted to apical margin, little homoplasy.

130: mesonotum anteromedian signum absent (Vilhelmsen et al., 2010, fig. 44D), convergently lost in some derived cynipoids and Proctotrupoidea.

361: hind wing with guide setae or spines posterior to hamuli. Only convergent in a few aculeates and absent in a few Diaprioidea.

Genes: Present in $18 \mathrm{~S}$ consensus tree with RS $=46$; also present in the $28 \mathrm{~S}$ tree, although without relative support. EF-1 $\alpha$ was not amplified for either of the Mymarommatoidea exemplars.

Alternatives: See Diaprioidea.

Conclusions: Monophyly of clade well supported.

\section{Diaprioidea}

History: First separated from Proctotrupoidea and proposed as a separate superfamily by Sharkey (2007) to include Maamingidae, Diapriidae, and Monomachidae. This is not to be confused with Rasnitsyn's (1980) concept of Diaprioidea, which comprised Platygastroidea, Mymaridae, Austroniidae, Diapriidae, Monomachidae and the extinct family Serphitidae. The first clear evidence for a relationship between Monomachidae and Diapriidae came from Dowton and Austin (2001), and was corroborated by Castro and Dowton (2006), in which the Bayesian analysis has a posterior probability of 0.99 . Heraty et al. (2011) recovered Diaprioidea in only two Bayesian $(\mathrm{PP}=0.98)$ and one parsimony analyses, whereas they were paraphyletic relative to Chalcidoidea in the remainder.

Total-evidence: Present in the consensus tree but without RS.

Morphology: No support found because Maaminga is nested within Chalcidoidea. The two morphological character states supporting monophyly on the totalevidence tree are 158(2), and 220(0), both of which are quite homoplastic within Proctotrupomorpha. A further two synapomorphies support Diaprioidea except Ismarus, i.e.,

6: subantennal shelf present.

222: metapleuron, ventral transverse carina: absent or weakly developed convergent in some members of most Proctotrupomorpha superfamilies.

The monophyly of Diapriidae except Ismarus is supported by six morphological character states not present in Ismarus, i.e., 64(1), 74(0), 84(1), 125(1), 215(1) and 252(1).

158: Mesophragma, number of mesolaterophragmal lobes $=2$, also in most Proctotrupoidea s. str. (Vilhelmsen et al., 2010, fig. 47F).

220: Metapleuron, lateral longitudinal carina absent; convergences occur in most Proctotrupomorpha superfamilies. 
Genes: Present in EF- $1 \alpha$ consensus tree, in which Ismarus is lacking, but without support. Present in the $18 \mathrm{~S}$ consensus tree with $\mathrm{RS}=28$, but including Mymarommatoidea as a derived unit (see Chalcidoidea + Mymarommatoidea). When not monophyletic, in individual gene trees, Ismarus is often the outlying taxon, e.g. in the COI support tree where it is sister group to Scolia, an aculeate. In the individual gene trees and the all-genes tree Diapriidae is never supported. Thus, when Diaprioidea is not supported it is a member of Diapriidae more often than Monomachus and Maaminga that is the cause.

Alternatives: The concept of Proctotrupoidea s.l., i.e., including Diaprioidea, does not appear in any of our analyses. The morphology support tree comes close to this conclusion with Diapriidae and Monomachus forming a basal grade to Proctotrupoidea $s$. str., but Maaminga is placed outside of this group.

Conclusions: Monophyly of Diaprioidea is well supported based on molecular evidence. Placement in a more inclusive Proctotrupoidea s.l. is not better supported by morphological data and it is contradicted by molecular data. Because Ismarus is often shown to be basal to the other members of the superfamily, e.g. the total-evidence consensus tree, or basal to members of Diapriidae, e.g. the total-evidence support tree, we suggest that it be elevated from subfamilial to familial status, Ismaridae stat. nov.

\section{Mymarommatoidea + Chalcidoidea}

History: First proposed by Gibson (1986) and subsequently by Gibson et al. (1999). Although absent in the unweighted results of Vilhelmsen et al. (2010), the relationship was present in two of their weighted trees. Ronquist et al. (1999) retrieved the clade with a bootstrap value of 94 . This represents the highest bootstrap value on their tree other than that for the monophyly of Ichneumonoidea. This same relationship was upheld in the "re-reanalysis" by Sharkey and Roy (2002) in which wing characters were edited. In Heraty et al. (2011), a sister group relationship between Mymarommatoidea + Chalcidoidea was recovered in the likelihood and parsimony analyses of the eye-alignment with third positions excluded.

Total-evidence: Present in the total-evidence consensus tree with RS $=65$.

Morphology: Our morphology-only support tree places Mymarommatoidea with Chalcidoidea, with symmetricresampling support of 24. However, this clade includes Maaminga, which is clearly misplaced (see Diaprioidea). In the total-evidence tree Mymarommatoidea + Chalcidoidea is supported by two uniquely derived character states, 57(0) and 140(1).

57: loss of all labial palpomeres, with a reversal in more derived and larger chalcidoids. This may be a case of parallel losses in taxa composed of small specimens.

140: mesonotum, axillar phragma present (Vilhelmsen et al., 2010, fig. 46A).

Sixteen homoplastic character states also show support, of which the following deserve mention:

18: occipital carina absent, with reversal in more derived and larger chalcidoids.

136: transscutal ridge present (Vilhelmsen et al., 2010, fig. 46A) with convergent occurrence in Maaminga as well as Diplolepis and Ibalia (Cynipoidea).

342: retinaculum with crenulae, convergent only in the aculeate Metapolybia. The most common state across the remainder of the Hymenoptera is a retinaculum with spicules.

Genes: Lacking obvious support.

Alternatives: Our 18S results place Mymarommatoidea nested within Diaprioidea as sister group to Monomachus with $\mathrm{RS}=42$. Vilhelmsen et al. (2010) frequently retrieved Mymarommatidae and Maamingidae as sister groups, but this might be due to shared character states correlated with small body size. Heraty et al. (2011) retrieved Mymarommatoidea as sister to Chalcidoidea + Diaprioidea with a posterior probability of 65. Most analyses in Heraty et al. (2011) placed Mymarommatoidea as the sister group of Diaprioidea + Chalcidoidea.

Conclusions: Strongly supported in the combined results. The Bayesian tree published by Heraty et al. (2011) shows Mymarommatoidea with the longest branch of any clade in the ingroup, and it is possible that long-branch attraction may be causing what little instability there is in its placement.

\section{Discussion}

The monophyly of most hymenopteran superfamilies has been established for a considerable time. Exceptions to this include Diaprioidea s. str., Proctotrupoidea $s$. str., Evanioidea, Siricoidea (including Anaxyelidae) and Xyeloidea, all of which are shown to be monophyletic in our results. The results section of this text gives further details of the support and history of these concepts. Our results show a paraphyletic Vespoidea, but unlike those of Pilgrim et al. (2008) it is in terms of not only Apoidea, but Chrysidoidea as well.

Well supported intersuperfamilial relationships include: Cephoidea [Siricoidea (Xiphydrioidea (Orussoidea + Apocrita))]; Ichneumonoidea is the sister group of Proctotrupomorpha; Platygastroidea is sister group to Cynipoidea, and together they are sister group to the remaining Proctotrupomorpha; Mymarommatoidea is the sister group of Chalcidoidea; Diaprioidea is sister group to Mymarommatoidea + Chalcidoidea, and a monophyletic Proctotrupoidea $s$. str. is sister group to 
this assembly. Weakly supported relationships include: Stephanoidea as the sister group of the remaining Apocrita; Aculeata as the sister group of Evanioidea; Ceraphronoidea as the sister group of Megalyroidea, which together form the sister group of [Trigonaloidea (Aculeata + Evanioidea)].

Using a supertree approach and published cladograms from the literature, Davis et al. (2010) generated a hypothesis of hymenopteran relationships. Their results for the symphytan taxa mirror ours almost exactly except for the reversed placement of Tenthredinoidea and Pamphilioidea. This reflects the comparative stability of basal hymenopteran relationships obtained within the last decade (see Vilhelmsen, 2006). Relationships among the apocritan superfamilies are in great contrast to ours with the following exceptions: Proctotrupomorpha is monophyletic; Cynipoidea is sister group to Platygastroidea; Diaprioidea is monophyletic and sister group to Chalcidoidea plus Mymarommatoidea. Significant differences include the following: Vespoidea is monophyletic; Mymarommatoidea is nested within the Chalcidoidea; Proctotrupoidea $s$ str. is not monophyletic; and Stephanoidea is nested within the Apocrita. The long established criticisms of supertrees (Goloboff and Pol, 2002) certainly vitiate their different results, which must be viewed as artifactual.

Rasnitsyn and Zhang (2010) described a number of new fossil apocritans and proposed an "intuitive" cladogram of apocritan relationships. There is little in common with our results for extant taxa other than some long-held views such as Orussoidea is the sister group to the Apocrita; and that Evanioidea (their Evaniomorpha) is monophyletic.

Our results do not support the conclusion that the ancestral behavior for Apocrita is ectoparasitism of wood-boring holometabolous larvae. Unlike the conclusions of Whitfield (1992) and Dowton and Austin (2001), the optimizations for endoparasitism versus ectoparasitism are equivocal in the basal Apocrita. These ambiguous regions are shown in red on Fig. 2. The long-held idea that ectoparasitism is ground-plan for Ichneumonoidea was due (in part) to the assumption that they constitute the sister group of Aculeata, but here, where they are placed as sister to the Proctotrupomorpha, the ground-plan for Ichneumonoidea is endoparasitism. This result is weakly supported due to its dependence on topologies within the families Braconidae and Ichneumonidae, where sampling is incomplete. It is further weakened by the lack of well supported relationships amongst members of the formerly recognized group Evaniomorpha. Despite our result (Fig. 2) the only convincing change between endoand ectoparasitism is that endoparasitism gave rise to ectoparasitism Chalcidoidea, as first suggested by Dowton and Austin (2001).
A surprising but convincing conclusion is that the Ichneumonoidea are sister group to the Proctotrupomorpha. The sister group relationship between Aculeata and Ichneumonoidea was not obtained in our total-evidence tree, nor was it retrieved in the morphology-only tree or in any of the molecular trees. In other words, there is little evidence that the Aculeata and Ichneumonoidea are sister groups and the presence of valvilli (small flaps along the egg canal/sting) is almost certainly convergent in the two taxa.

\section{Acknowledgements}

This research was supported by National Science Foundation Grants EF-0337220, EF-0341708, EF0341149 and DEB-0730616. Thanks to the following for providing us with specimens and/or identifications: Celso Azevedo, Denis Brothers, Brian Brown, Matt Buffington, James Cuda, John Early, Brian Fisher, Gary Gibson, Masatsugu Hatakeyama, Stephen Hight, John Huber, Lubomir Masner, Tikahiko Naito, Manfred Niehuis, Michael Ohl, James Pitts, Donald Quicke, Nathen Schiff, David Smith, David Wahl and Phil Ward. Thanks to Matt Buffington and two anonymous referees for their helpful reviews. Finally, we salute Alex Rasnitsyn for his pioneering research on the phylogeny of Hymenoptera.

\section{References}

Carpenter, J.M., Wheeler, W.C., 1999. Towards simultaneous analysis of morphological and molecular data in Hymenoptera. Zool. Scr. 28, 251-260.

Castro, L.R., Dowton, M., 2006. Molecular analyses of Apocrita (Insecta: Hymenoptera) suggest that the Chalcidoidea are sister to the diaprioid complex. Invertebr. Syst. 20, 603-614.

Davis, R.B., Baldauf, S.L., Mayhew, P.J., 2010. The origins of species richness in the Hymenoptera: insights from a family-level supertree. BMC Evol. Biol. 10, 1-16.

Dowton, M., Austin, A.D., 1994. Molecular phylogeny of the insect order Hymenoptera: Apocritan relationships. Proc. Natl Acad. Sci. USA 91, 9911-9915.

Dowton, M., Austin, A.J., 2001. Simultaneous analysis of 16S, 28S, COI and morphology in the Hymenoptera: Apocrita - evolutionary transitions among parasitic wasps. Biol. J. Linn. Soc. 74, 87-111.

Dowton, M., Austin, A.D., Dillon, N., Bartowsky, E., 1997. Molecular phylogeny of the apocritan wasps: the Proctotrupomorpha and Evaniomorpha. Syst. Entomol. 22, 245-255.

Freudenstein, J.V., Davis, J.I., 2010. Branch support via resampling: an empirical study. Cladistics 26, 643-656.

Gibson, G.A.P., 1986. Evidence for monophyly and relationships of Chalcidoidea, Mymaridae and Mymarommatidae (Hymenoptera: Terebrantes). Can. Entomol. 118, 205-240.

Gibson, G.A.P., Heraty, J.M., Woolley, J.B., 1999. Phylogenetics and classification of Chalcidoidea and Mymarommatoidea - a review of current concepts (Hymenoptera: Apocrita). Zool. Scr. 28, 87124. 
Goloboff, P.A., 1999. Analyzing large data sets in reasonable times: solutions for composite optima. Cladistics 15, 415-428.

Goloboff, P.A., Pol, D., 2002. Semi-strict supertrees. Cladistics 18, 514-525.

Goloboff, P.A., Farris, J.S., Källersjö, M., Oxelman, B., Ramirez, M.J., Szumik, C.A., 2003. Improvements to resampling measures of group support. Cladistics 19, 324-332.

Goloboff, P.A., Farris, J.S., Nixon, K.C., 2008. TNT, a free program for phylogenetic analysis. Cladistics $24,1-13$.

Heraty, J., Ronquist, F., Carpenter, J.M., Hawks, D., Schulmeister, S., Dowling, A.P., Murray, D., Munro, J., Wheeler, W.C., Schiff, N., Sharkey, M.J. 2011. Evolution of the hymenopteran megaradiation. Molecular Phylogenetics and Evolution 60, 73-88.

Johnson, N.F., 1988. Midcoxal articulations and the phylogeny of the order Hymenoptera. Ann. Entomol. Soc. Am. 81, 870-881.

Königsmann, E., 1976. Das phylogenetische System der Hymenoptera. Teil 1: Einfuhrung, Grundplanmerkmale, Schwestergruppe und Fossilfunde. Deutsche Entomologische Zeitschrift 23, 253279.

Königsmann, E., 1977. Das phylogenetische System der Hymenoptera. Teil 2: Symphyta. Deutsche Entomologische Zeitschrift 24, $1-40$.

Königsmann, E., 1978a. Das phylogenetische System der Hymenoptera. Teil 3: Terebrantes (Unterordnung Apocrita). Deutsche Entomologische Zeitschrift 25, 1-55.

Königsmann, E., 1978b. Das phylogenetische System der Hymenoptera. Teil 4: Aculeata (Unterordnung Apocrita). Deutsche Entomologische Zeitschrift 25, 365-435.

Maddison, W.P., Maddison, D.R. 2009. Mesquite: a modular system for evolutionary analysis, version 2.6. Available at http://mesquiteproject.org

Masner, L., 1956. First preliminary report on the occurrence of genera of the group Proctotrupoidea (Hym.) in SR. (First part Scelionidae). Acta Faunica Entomologica Musei Nationalis Pragae $1,99-126$.

Nixon, K.C., 1999. The Parsimony Ratchet, a new method for rapid parsimony analysis. Cladistics $15,407-414$.

Nixon, K.C., 2008. Winclada Ver. 1.7. Published by the author, Ithaca, New York, USA.

Nixon, K.C., Carpenter, J.M., 1996. On simultaneous analysis. Cladistics 12, 221-241.

Pilgrim, E., von Dohlen, C., Pitts, J., 2008. Phylogenetics of the stinging wasps (Hymenoptera: Vespoidea). Zool. Scr. 37, 539-560.

Rasnitsyn, A.P., 1969. Origin and evolution of the lower Hymenoptera. Trudy Paleontologicheskogo Instituta Akademii Nauk SSSR 123, 1-196. [in Russian]

Rasnitsyn, A.P., 1980. Origin and evolution of Hymenoptera. Trudy Paleontologicheskogo Instituta Akademiya Nauk SSSR 174, 1192. [in Russian]

Rasnitsyn, A.P., 1988. An outline of evolution of hymenopterous insects (order Vespida). Oriental Insects 22, 115-145.

Rasnitsyn, A.P., Zhang, H., 2010. Early evolution of Apocrita (Insecta, Hymenoptera) as indicated by new findings in the middle Jurassic of Daohuou, northeast China. Acta Geol. Sinica 84, 834-873.

Ronquist, F., Rasnitsyn, A.P., Roy, A., Eriksson, K., Lindgren, M., 1999. Phylogeny of the Hymenoptera: a cladistic reanalysis of Rasnitsyn's (1988) data. Zool. Scr. 28, 13-50.

Schulmeister, S., 2003. Simultaneous analysis of basal Hymenoptera (Insecta): introducing robust-choice sensitivity analysis. Biol. J. Linn. Soc. 79, 245-275.

Schulmeister, S., Wheeler, W.C., Carpenter, J.C., 2002. Simultaneous analysis of the basal lineages of Hymenoptera (Insecta) using sensitivity analysis. Cladistics 18, 455-484.

Sharanowski, B.J., Robbertse, B., Walker, J., Voss, S.R., Yoder, R., Spatafora, J., Sharkey, M.J., 2010. Expressed sequence tags reveal Proctotrupomorpha (minus Chalcidoidea) as sister to Aculeata (Hymenoptera: Insecta). Mol. Phylogenet. Evol. 57, 101-112.
Sharkey, M., 2007. Phylogeny and classification of Hymenoptera. Zootaxa 1668, 521-548.

Sharkey, M.J., Roy, A., 2002. Phylogeny of the Hymenoptera: a reanalysis of the Ronquist et al. (1999) reanalysis, with an emphasis on wing venation and apocritan relationships. Zool. Scr. 31, 57-66.

Vilhelmsen, L., 1997. The phylogeny of the lower Hymenoptera (Insecta), with a summary of the early evolutionary history of the order. J. Zool. Syst. Evol. Res. 35, 49-70.

Vilhelmsen, L., 2000. Cervical and prothoracic skeleto-musculature in the basal Hymenoptera (Insecta): comparative anatomy and phylogenetic implications. Zool. Anz. 239, 105-138.

Vilhelmsen, L., 2001. Phylogeny and classification of the extant basal lineages of the Hymenoptera (Insecta). Zool. J. Linn. Soc. 131, 393-442.

Vilhelmsen, L., 2006. Developments in 'symphytan' phylogenetics in the 20th century: towards a consensus. In: Blank, S.M., Schmidt, S., Taeger, A. (Eds), Recent Sawfly Research: Synthesis and Prospects. Goecke \& Evers, Kelten, Germany, pp. 31-38.

Vilhelmsen, L.. in press. Head capsule characters in the Hymenoptera (Insecta) and their phylogenetic implications. ZooKeys.

Vilhelmsen, L., Mikó, I., Krogmann, L., 2010. Beyond the wasp-waist: structural diversity and phylogenetic significance of the mesosoma in apocritan wasps (Insecta: Hymenoptera). Zool. J. Linn. Soc. 159, 22-194.

Whitfield, J.B., 1992. Phylogeny of the non-aculeate Apocrita and the evolution of parasitism in the Hymenoptera. J. Hymenopt. Res. 1, $3-14$.

\section{Appendix 1}

\section{Character list}

Abbreviations: S, sternum; e.g., S1, abdominal sternum 1; T, tergum.

\section{Head}

1. Ocellar corona: absent $=0$; present $=1$.

2. Supraantennal groove or depression: absent $=0$; present, accommodating scapes $=1$.

3. Notch on medial margin of eye: absent $=0$; present $=1$.

4. Position of toruli relative to eyes: below or level with lower margin of eyes $=0$; above lower margin of eyes $=1$.

5. Position of toruli relative to clypeus: equal or closer to clypeus than its own diameter $=0$; further from clypeus than its own diameter $=1$.

6. Subantennal shelf: absent $=0$; present, toruli facing upwards $=1$. 7. Inner margin of torulus: not distinctly raised compared to outer margin $=0$; with distinct projection, raised compared to outer margin $=1$; area between projections raised forming interantennal process $=2$. [additive]

8. Subantennal groove: absent or weakly developed $=0$; present, distinct $=1$.

9. Clypeus: not inflected $=0$; inflected, covering base of labrum $=1$. 10. Mandibular foramen: absent, oral and mandibular foramen continuous $=0$; mandibular and oral foramina separated by subgenal sclerotization $=1$.

11. Occipital sulcus and ridge: absent $=0$; present $=1$.

12. Position, occipital foramen: approximately halfway between top of head and oral foramen $=0$; distance from top of head to occipital foramen half or less than half distance to oral foramen $=1$.

13. Position, posterior tentorial pits: adjacent/at level with occipital foramen $/$ condyles $=0$; considerably ventral to occipital foramen $=1$. 14. Sclerotization between occipital and oral foramina: absent, foramina confluent $=0$; present, foramina separate $=1$. 
15. Ventral sclerotization configuration: at most oblique ventral to tentorial pits, not extending anteriorly $=0$; horizontal ventral to pits and extending anteriorly $=1$.

16. Postoccipital bridge: absent $=0$; bridge connecting insertion points of the ventral profurco-postoccipital muscles ventrad the tentorial bridge present $=1$.

17. Longitudinal sulci on ventral head sclerotization: none $=0$; one median sulcus or hair line present, at least ventrally $=1$; two sublateral sulci present, not merging ventrally $=2$. [nonadditive]

18. Occipital carina: absent $=0$; present $=1$.

19. Occipital carina configuration: reaching ventral margin of head capsule $=0$; not reaching ventral margin of head capsule and not continuous medially $=1$; not reaching ventral margin of head capsule and continuous ventrad occipital foramen $=2$. [nonadditive]

20. Dorsal tentorial arm: absent or reduced, not reaching head capsule $=0$; present, in contact with head capsule anteriorly $=1$.

21. Shape, tentorial bridge: broad, not above level of posterior tentorial arms $=0$; slender, arched above posterior tentorial arms $=1$.

22. Corpotendon on tentorial bridge: absent $=0$; present anteriorly on tentorial bridge $=1$.

\section{Mouthparts}

23. Position of labrum: anterior to tips of mandibles $=0$; posterior to tips of mandibles $=1$.

24. Shape of labrum: transverse $=0$; trapezoidal $=1$; thin and cylindrical $=2$; long, thin and flattened $=3$; transverse, planar and weakly sclerotized to membranous $=4$; triangular $=5$; membranous $\mathrm{sac}=6$; transverse with narrow medial projection $=7$. [nonadditive] 25. Labrum: present $=0$; absent $=1$.

26. Exposure of labrum: exposed $=0$; concealed $=1$.

27. Distal epipharyngeal wall: not sclerotized $=0$; sclerotized and continuous with labrum $=1$.

28. Lateral epipharyngeal brush: absent $=0$; present $=1$.

29. Epipharyngenal lobe: absent $=0$; present $=1$.

30. Epipharyngeal setae: absent $=0$; present $=1$; dense medial patch of stout setae $=2$. [nonadditive]

31. Tormae: distinct apodemes continuous with labrum, not continuous medially $=0$; present, continuous medially $=1$; absent $=2$. [nonadditive]

32. Sclerotization of labrum: heavily sclerotized $=0$; weakly sclerotized $=1 ;$ membranous $=2$. [nonadditive]

33. Thickness of labrum: thick, inner and outer surfaces separate $=0$; flattened, inner and outer surfaces apressed $=1$.

34. Labral setation: scattered setae over anterior surface $=0$; setae restricted to apical margin $=1$; bare $=2$. [nonadditive]

35. Labral apodemes: absent $=0$; present, long and thick $=1$; present, short, thin and articulating with head capsule $=2$. [nonadditive]

36. Sitophore: absent $=0$; present, does not extend distally of the functional mouth $=1$; present, extends distally of the functional mouth $=2$.

37. Sitophore sensillae: absent $=0$; patch of more than 4 lateral sensillae present $=1$.

38. Hypopharyngeal lobe: absent $=0$; present $=1$.

39. Infrabuccal pouch: small and/or with inconspicuous armature $=0$; large, with distinct cuticular teeth developed for grinding pollen $=1$; forming a distinct gnathal pouch $=2$. [nonadditive] 40. Hypopharyngeal pectens: absent $=0$; minute hairs on hypopharyngeal rods $=1$; distinct brushes present on hypopharyngeal rods $=2$. [additive]

41. Left mandible dentition: unidentate $=0$; one extra tooth [bidentate $=1$; two extra teeth $[$ tridentate $]=2$; four or more distinct teeth $=3$. [nonadditive]

42. Dentition of right mandible relative to left: one tooth less on right mandible $=0$; equal number of teeth on both mandibles $=1$.

43. Mola on right mandible: present $=0$; absent $=1$.
44. Mandibular peg on ventral margin: absent $=0$; present $=1$. 45. Mandibular rods/glands: absent $=0$; present $=1$.

46. Lateral articulation of mandible: with distinct posterolateral condyle $=0$; truncate connection $=1$; medial condyle $=2$; anterolateral condyle $=3$. [nonadditive]

47. Lateral mandibular muscle attachment: hidden $=0$; visible externally $=1$.

48. Shape of glossa (alaglossa): lobate $=0$; flat $=1$; folded into an inverted U-shape $=2$; hood-like and folded medially $=3$; semispherical $=4$; absent or much reduced $=5$. [nonadditive]

49. Setation of glossa: scattered setae $=0$; distinct rows of flattened setae $=1$; bare $=2$; densely setose $=3$. [nonadditive]

50. Glossal fringe: absent $=0$; present $=1$.

51. Submarginal setae of glossa: absent $=0$; present $=1$.

52. Campaniform sensillae of glossa: absent $=0$; present $=1$.

53. Acroglossal button: absent $=0$; present $=1$.

54. Glossal margin: entire $=0$; slightly emarginate $=1$; deeply incised $=2$. [additive]

55. Paraglossae: club-shaped, without microtrichia $=0$; lobate with setae or flattened scale-like microtrichia in transverse rows $=1$, flattened with scale-like microtrichia in transverse rows $=2$; distal scale-bearing part reduced $=3$; totally reduced, fused with glossa $($ Siricidae $)=4$. [nonadditive]

56. Paraglossal basal setation: setose or bare $=0$; spinose $=1$.

57. Number of labial palp segments: none $=0$; one $=1$; two $=2$; three $=3$; four $=4$. [nonadditive]

58. Rod-like sensilla: absent $=0$; specialized sensilla on distal labial palp segment present $=1$; present, situated in invagination with pore opening $=2$. [nonadditive]

59. Subapical sensilla on basal palpomere: absent $=0$; present $=1$.

60 . Postmentum: present $=0$; absent $=1$; faint trace $($ Sapygidae $)=$ 2 [nonadditive]

61. Number of maxillary palp segments: none $=0$; one $=1$; two $=2$; three $=3$; four $=4$; five $=5$; $\operatorname{six}=6$. [nonadditive]

62. Maxillary palp shape: thin, not leg-like $=0$; thick, leg-like, with a setae-bearing distal part $=1$.

63. Sensillum on third maxillary palpomere: absent $=0$; present $=1$. 64. Third maxillary palpomere: cylindrical $=0$; enlarged, broader than the following palpomere, and triangular $=1$.

65. Shape of lacinia: rounded $=0$; acuminate $=1$.

66. Galea shape: entire $=0$; divided and broad $=1$; divided and longitudinally elongate $=2$; absent $=3$. [nonadditive]

67. Galea division: with two apices $=0$; unipartite $=1$.

68. Stipes sensillum: absent $=0$; single prominent sensillum $=1$.

\section{Pronotum (thorax)}

69. Pronotum shape anteriorly: protruding $=0$; reduced $=1$.

70. Pronotum, anteroventral longitudinal carinae: absent $=0$; two parallel carinae with concave area between them present $=1$.

71. Pronotum, submedian depressions: absent $=0$; pits corresponding to internal concavities present $=1$.

72. Pronotum, length: long dorsad transverse sulcus $=0$; short dorsad transverse sulcus $=1$.

73. Pronotum orientation: pronotum posterad transverse sulcus oblique $=0$; pronotum posterad transverse sulcus vertical $=1$.

74. Pronotum, transverse carina: absent $=0$; present, traversing pronotum dorsad transverse sulcus $=1$.

75. Pronotum, anterior surface: convex or straight, not accommodating head $=0$; concave, smooth, delimited by lateral projections, accommodating head $=1$.

76. Pronotum, dorsomedially: without shelf $=0$; with smooth shelf accommodating prophragma $=1$.

77. Pronotum, submedian apodemes: absent $=0$; small apodemes present $=1$.

78. Pronotum, anterolateral corners: rounded $=0$; with distinct notch accommodating anterolateral corner of mesoscutum $=1$. 
79. Pronotum, anterolateral internal carina: absent or weakly developed $=0$; distinct transverse carina present anterolaterally $=1$.

80. Pronotum, posterodorsal corner: without notch $=0$; with notch above anterior spiracle, accommodating tegula $=1$.

81. Pronotum, posterolateral margin: with incurvation accommodating anterior spiracle $=0$; straight $=1$; with extended lobe $=2$. [nonadditive]

82. Pronotum, anterior spiracle: visible, posterior to posterolateral margin of pronotum $=0$; hidden by posterolateral margin of pronotum $=1$; visible, surrounded by continuous cuticle $=2$. [nonadditive] 83. Pronotum, mesopleural attachment: movable relative to mesopleuron, or not abutting $=0$; rigidly attached to mesopleuron $=1$.

84. Pronotum, lateroventral corners: not projecting medially $=0$; with medial inflexions abutting mesopleuron $=1$; fused, forming bridge behind procoxae $=2$. [additive]

\section{Prepectus (thorax)}

85. Prepectus: absent $=0$; present as an independent sclerite $=1$. 86. Prepectus: exposed $=0$; concealed $=1$.

87. Prepectus, pronotal inflection: absent $=0$; present $=1$.

88. Prepectus/inflection, dorsal extent: not extending dorsad anterior spiracle $=0$; extending dorsad anterior spiracle $=1$.

89. Prepectus/inflection, ventral configuration: separate or at most slightly abutting $=0$; broadly abutting $=1$; fused together or with prospinasternum $=2$. [additive]

90. Position of occlusor muscle apodeme: midway on posterolateral pronotal margin $=0$; ventrally on posterolateral pronotal margin $=1$.

91. Position, anterior thoracic spiracle: more than one spiracular diameter from posterodorsal corner of pronotum $=0$; at posterodorsal corner of pronotum $=1$; dorsally between pronotum and mesoscutum $=2$. [additive]

92. Projection ventrad anterior spiracle: absent $=0$; narrow projection ventrad spiracle present $=1$.

\section{Propectus (thorax)}

93. Propleura, cervical prominences: not retracted, cervical swellings exposed $=0$; retracted, swellings concealed $=1$.

94. Propleura, position of cervical prominences: at anterodorsal corners of propleura $=0$; ventrad anterodorsal corners of propleura $=1$.

95. Propleuron, cervical apodeme: entirely absent $=0$; short, inconspicuous $=1$; well developed, distinct $=2$. [additive]

96. Propleuron, cervical apodeme configuration: separate from propleura posteriorly $=0$; curves laterally to fuse with propleura posteriorly $=1$.

97. Propleuron, cervical lines: laterocervicalia and propleuron proper at most articulating $=0$; laterocervicalia and propleuron partly fused, cervical line present $=1$; laterocervicalia and propleuron completely fused, cervical line absent $=2$. [additive]

98. Propleura, dorsal part: not inflected, sculpture similar to rest of propleura $=0$; inflected with smooth or shagreened sculpture $=1$.

99. Dorsal margins of propleura: widely separated for most of their length $=0$; abutting for at least half their length $=1$.

100. Propleuron, propleural arm: absent $=0$; present $=1$.

101. Configuration of propleural arms: erect, not abutting profurca posteriorly $=0$; horizontal, extending medially posterad profurca $=1$. 102. Propleura, lateroventral carina: absent $=0$; longitudinal carina on lateroventral margin of propectus present $=1$.

103. Propleura, median margins: widely separate for their entire length $=0$; diverging posteriorly, prosternum broadly exposed $=1$; abutting for most of their length, prosternum partly concealed $=2$. [additive]
104. Propleura, epicoxal lobes: posterolateral corner of propleuron not extended $=0$; extended as epicoxal lobe, covering procoxa proximally $=1$.

105. Propleura, posterolateral groove: absent $=0$; distinct groove dorsally on corners, articulating with pronotum $=1$.

106. Propleura, prothoracic katepisterna: absent $=0$; present $=1$.

107. Propleuron, katepisternum configuration: abutting propleuron at articulation with procoxa $=0$; separated from propleuron $=1$.

108. Prosternum, anteroventral part: at most extending slightly anterior to posterior margin of propleura $=0$; extending well anterior to posterior margin of propleura $=1$.

109. Prosternal spine: absent $=0$; median posteriorly-directed spine present $=1$.

110. Prosternum, laterosternal sclerites: absent $=0$; present $=1$.

111. Prosternum, subdivision: not subdivided $=0$; transversely subdivided dorsally by deep lateral incisions $=1$.

112. Profurca, number of profurcal pits: one $=0$; two $=1$.

113. Profurca, anterior apodemes: absent or weakly developed $=0$; well developed, continuous with tendons $=1$.

114. Profurca, bridge: absent $=0$; present and low $=1$; present and high, curving posteriorly $=2$. [nonadditive]

115. Profurca, articulation with propleuron: lateral profurcal arm not articulating with propleuron $=0$; lateral profurcal arm articulating with propleuron posterodorsally $=1$.

\section{Foreleg (thorax)}

116. Foreleg, procoxa: broad basally, proximal foramen width at least half maximal width of procoxa $=0$; constricted basally, proximal foramen width less than half maximal width $=1$.

117. Foreleg, procoxal transverse carina: absent $=0$; developed for at least part of coxa $=1$.

118. Foreleg, protibial furrow: absent $=0 ; \quad$ U-shaped furrow present $=1$.

119. Foreleg, calcar: anterior apical protibial spur unmodified $=0$; anterior apical protibial spur modified into calcar for antenna cleaning $=1$.

120. Foreleg, posterior apical protibial spur: absent or reduced $=0$; present $=1$.

121. Foreleg, probasitarsal notches: absent $=0$; present $=1$.

122. Foreleg, probasitarsal combs: absent or weakly developed $=0$; present, well developed $=1$.

123. Foreleg, probasitarsal spur: absent $=0$; present $=1$.

\section{Mesonotum (thorax)}

124. Mesonotum, prophragma: absent or reduced $=0$; well developed $=1$.

125. Mesonotum, prophragma shape: bilobed $=0$; not subdivided by slit $=1$.

126. Mesonotum, prophragma laterally: not extended, higher submedially than laterally $=0$; extended, higher laterally than submedially $=1$.

127. Mesonotum, anterior mesoscutal sulcus: absent $=0$; transverse groove accommodating dorsal margin of pronotum present $=1$.

128. Mesonotum, anterior mesoscutal sulcus configuration: at most extending slightly onto prophragma anteromedially $=0$; with distinct ventral extension onto prophragma anteromedially $=1$.

129. Mesonotum, median mesoscutal sulcus and ridge: both external sulcus and internal ridge well developed $=0$; only sulcus developed $=1$; both sulcus and ridge absent, at least posteriorly $=2$. [additive] 130. Mesonotum, anteroadmedian signum: absent $=0$; present $=1$. 131. Mesonotum, notauli: well developed internally and externally $=$ 0 ; developed only externally $=1$; absent, at least posteriorly $=2$. [additive] 
132. Mesonotum, notauli configuration: separate, not joining prior to reaching transscutal articulation $=0$; converging medially and joining prior to reaching articulation $=1$; merged into $\mathrm{U}$-shaped sulcus, not reaching articulation $=2$. [additive]

133. Mesonotum, parapside: absent $=0$; present $=1$.

134. Mesonotum, parascutal carina: absent $=0$; area accommodating tegula delimited by longitudinal carina present $=1$.

135. Mesonotum, transscutal articulation: absent $=0$; present, not less sclerotized than adjacent cuticle $=1$; present, less sclerotized than adjacent cuticle $=2$. [additive]

136. Mesonotum, transscutal carina: absent $=0$; present $=1$.

137. Mesonotum, size of dorsal axillar surface: large, mesoscutellar sulcus $\mathrm{U}$ - or $\mathrm{V}$-shaped $=0$; small, mesoscutellar sulcus straight medially $=1$.

138. Mesonotum, axillar carina: absent $=0 ;$ longitudinal carina extending dorsally from scutellar arm present $=1$.

139. Mesonotum, lateral corners of axilla: rounded, no distinct projection dorsally $=0$; axillar carina with distinct posterior projection dorsally $=1$.

140. Mesonotum, axillar phragma: absent $=0$; present $=1$.

141. Mesonotum, scutoscutellar sulcus: configuration variable, may consist of impressed line or row of small depressions, but never one or two large depressions $=0$; consisting of one or two wide depressions with small pits laterally $=1$.

142. Mesonotum, mesoscutellar carina: absent or weakly developed medially $=0$; present, distinct throughout $=1$.

143. Mesonotum, configuration of mesoscutellar carina: reaching transscutal carina/articulation medially $=0$; not reaching transscutal carina/articulation $=1$.

144. Mesonotum, internal median longitudinal mesoscutellar carina: absent $=0$; present $=1$.

145. Mesonotum, internal septum: absent $=0$; septum with small fenestrum spanning at least part of mesoscutellum ventrally $=1$.

146. Mesonotum, longitudinal subdivision of scutellum: not subdivided $=0$; subdivided by submedian longitudinal grooves $=1$. 147. Mesonotum, frenum: mesoscutellum not subdivided $=0$; mesoscutellum transversely subdivided by line, fold, or carina $=1$.

148. Mesonotum, mesoscutellum posteriorly: not as state $1=0$; medially with row of sculptured depressions $=1$.

149. Mesonotum, mesoscutellar appendage: absent or weakly developed $=0$; projection, separated from scutellum by distinct line, present $=1$.

150. Mesonotum, mesoscutellar arm configuration: narrow, erect, slender $=0$; broad, low, smooth $=1$.

151. Mesonotum, origin of mesoscutellar arms: at posterolateral corners of mesoscutellum $=0$; anterolaterally on mesoscutellum $=1$. 152. Mesonotum, mesoscutellar arm distally: not extending $=0$; distinctly extended laterally $=1$.

\section{Mesophragma (thorax)}

153. Mesophragma, pseudophragmal lobe(s): absent or weakly developed $=0$; well developed, distinct lobes $=1$.

154. Mesophragma, anterior margin position: at most displaced slightly posterior to posterior margin of mesoscutellum $=0$; displaced posteriorly into propodeum for at least the length of the mesoscutellum $=1$.

155. Mesophragma, mesophragmal pockets: weakly developed, no curved line anterodorsally on mesophragma $=0$; well developed, with deeply curved posterior margin $=1$.

156. Mesophragma, median longitudinal carina: absent or weakly developed $=0$; distinct carina extending ventrally along most of phragma $=1$.

157. Mesophragma, mesolaterophragmal lobes: reduced or absent $=0$; present, well developed $=1$.

158. Mesophragma, number of mesolaterophragmal lobes: one $=0$; two $=1$.
159. Mesophragma, mesolaterophragmal apodeme shape: short, rounded $=0$; elongate, slender $=1$.

160. Mesophragma, mesopostnotum: exposed $=0$; concealed by anterior part of metanotum $=1$.

161. Mesophragma, lateral attachment of mesopostnotum: broad, exposed $=0$; invaginated, but still developed $=1$; reduced, mesopostnotum entirely internal $=2$. [additive]

162. Mesophragma, lateral flanges: absent $=0$; distinct flanges present anteromedially $=1$.

\section{Mesopectus (thorax)}

163. Mesopectus, configuration with mesonotum: not broadly abutting, tegula and pronotum adjacent $=0$; abutting for considerable distance, tegula well separated from pronotum $=1$.

164. Mesopectus, tegula configuration: exposed $=0$; concealed by dorsolateral corner of pronotum $=1$.

165. Mesopleuron, external part of basalar: not enlarged $=0$; conspicuously enlarged, extending ventrad anterior spiracle $=1$.

166. Mesopleuron, basalar apodeme: large, cup-shaped $=0$; reduced, tendon-like $=1$.

167. Mesopleuron, postspiracular sclerite: absent $=0$; present $=1$.

168. Mesopleuron, posterior thoracic spiracle configuration: exposed, in concavity in mesopleural margin $=0$; exposed, above mesopleural margin $=1$; not visible externally $=2$. [nonadditive]

169. Mesopleuron, supramesopleural sclerite: absent $=0$; sclerite between mesopleuron and metapleural arm present $=1$.

170. Mesopleuron, mesepimeral ridge: absent or weakly developed $=0$; distinct ridge extending from dorsal margin of mesopleuron to approximately halfway to mesocoxal articulation $=1$; distinct ridge extending from dorsal margin of mesopleuron to mesocoxal articulation $=2$. [additive]

171. Mesopectus, mesopleural ridge: absent $=0$; ridge extending between anterior margin of mesopleuron and mesocoxal articulation $=1$.

172. Mesopleuron, mesopleural pit: absent $=0$; small pit present $=1$. 173. Mesopleuron, mesopleural apodeme: absent or weakly developed $=0$; apodeme present $=1$.

174. Mesopleuron, apodeme configuration: separate from mesepimeral ridge $=0$; continuous with mesepimeral ridge $=1$.

175. Mesopectus, mesopleural triangle: at most slight depression present dorsally on mesopleuron $=0$; distinct triangular depression extending across dorsal mesopleuron $=1$.

176. Mesopleuron, prospinasternum: separate sclerite $=0$; fused with mesopleuron and/or pronotum $=1$.

177. Mesopleuron, prospinasternal apodeme: absent $=0$; present, well developed $=1$.

178. Mesopleuron, acetabular/epicnemial carina: absent or weakly defined $=0$; distinct, extending below procoxae $=1$.

179. Mesopleuron, procoxal concavities: absent or weakly developed $=0$; concavities accommodating procoxae present $=1$.

180. Mesopleuron, subpleural signum: absent $=0$; longitudinal line or crease present $=1$.

181. Mesopectus, pseudosternal sulci: absent or not developed internally $=0$; well developed internally and externally $=1$.

182. Mesopectus, sternaular carina: absent or weakly developed $=0$; oblique internal carina on mesepisternum present $=1$.

183. Mesopleuron, posterior transverse carina: absent $=0$; present, delimiting concave or smooth area just anterior to mesocoxal foramina $=1$.

184. Mesopleuron, mesocoxal foramina: widely open dorsally, not surrounded by mesopleural cuticle $=0$; foramen constricted, but still with narrow opening dorsally $=1$; closed dorsally, surrounded by continuous mesopleural cuticle $=2$. [additive]

185. Mesopleuron, median mesocoxal articulation: absent $=0$; present, on projection $=1$. 
186. Mesopleuron, medial mesocoxal articulation position: situated on proximal rim of mesocoxa, articulations not elongated $=0$; situated distally, on medial surface of mesocoxa $=1$.

187. Mesofurca, mesofurcal pit: situated at level with mesocoxal foramina $=0$; situated anterior to mesocoxal foramina $=1$.

188. Mesofurca, mesospina and metafurco-mesospinal muscle: absent $=0$; present, short, erect $=1$; elongate, projecting posteriorly between metafurcal arms $=2$. [additive]

189. Mesofurca, arms proximally: with at most shallow depressions $=0$; with distinct concavities dorsally $=1$.

190. Mesofurca, anterior arm: short, inconspicuous $=0$; elongate $=1$. 191. Mesofurca, bridge $(\mathrm{R} 99,54)$ : absent $=0$; present $=1$.

192. Mesofurca, anterior projection on bridge: absent $=0$; present $=1$.

193. Mesofurca, lateral arm: short, not extending towards mesopleuron $=0$; elongate, extending towards mesopleuron $=1$.

\section{Midleg (thorax)}

194. Midleg, mesocoxa: not subdivided $=0$; subdivided $=1$.

195. Midleg, proximal part of mesocoxa: well developed $=0$; much reduced $=1$.

196. Midleg, coxo-trochanter articulation: broad, trochanter cylindrical proximally $=0$; narrow, trochanter with flattened disk proximally $=1$.

197. Midleg, trochantellus: absent $=0$; femur subdivided proximally, forming small trochantellus $=1$.

\section{Metanotum (thorax)}

198. Metanotum: reduced, antecostal sulcus adjacent to mesoscutellum $=0$; well developed, antecostal sulcus well separated from mesoscutellum $=1$.

199. Metanotum, orientation: more or less horizontal, angled less than $90^{\circ}$ relative to mesoscutellum $=0$; vertical, angled $90^{\circ}$ relative to mesoscutellum $=1$.

200. Metanotum, cenchri: absent $=0$; present $=1$.

201. Metanotum, hind wing tegula: absent $=0$; present $=1$.

202. Metanotum, humeral sclerite: absent, anterior metanotal wing process continuous with remainder of metanotum $=0$; anterior metanotal wing process situated on separate sclerite $=1$.

203. Metanotum, metascutellum: absent or reduced $=0$; present, well developed $=1$.

204. Metanotum, metascutellum configuration: reaching anterior margin of metanotum, abutting mesoscutellum $=0$; not reaching anterior margin of metanotum $=1$.

205. Metanotum, incurvation posterad metascutellum: at most weakly developed $=0$; present, distinct $=1$.

206. Metanotum, lateral longitudinal carina: absent or reduced, not traversing metanotum $=0$; well developed, traversing entire metanotum $=1$.

207. Metanotum, lateral incision: absent $=0$; anterolateral membranous area present $=1$.

\section{Metapectus (thorax)}

$\mathrm{T} 1$ is the first abdominal tergum, corresponding to the propodeum in the Apocrita.

208. Metapleuron, apodemal part of metabasalare: absent or reduced $=0$; present, independent cup-shaped sclerite $=1$; present, continuous with metapleuron $=2$. [additive]

209. Metapleuron, metapleural arm-T1 association: not abutting $\mathrm{T} 1=0$; abutting $\mathrm{T} 1=1$; fused with $\mathrm{T} 1=2$. [additive]

210. Metapleuron, metapleural arm configuration: continuous with rest of metapleuron $=0$; separated from rest of metapleuron by anterolateral part of $\mathrm{T} 1=1$.
211. Metapleuron, metepisternal anapleural cleft: absent $=0$; present $=1$.

212. Metapleuron, metepimeron-T1 association: at most fused for short distance $=0$; broadly fused $=1$.

213. Metapleuron, metepimeron: well developed throughout $=0$; reduced posteriorly $=1$.

214. Metapleuron, articular inflection: absent $=0$; present $=1$.

215. Metapleuron, dorsal longitudinal ridge: absent $=0$; distinct ridge ventral to propodeal spiracle present $=1$.

216. Metapleuron, metapleural pit: entirely absent $=0$; at least shallow depression present $=1$.

217. Metapleuron, metapleural apodeme: absent or weakly developed $=0$; present, well developed $=1$.

218. Metapleuron, mesopleural-metapleural association: may articulate or abut ventrally, but not fused $=0$; fused ventrally $=1$; fused ventrally and laterally $=2$. [additive]

219. Metapleuron, paracoxal notches: absent $=0$; present $=1$.

220. Metapleuron, median longitudinal carina/projection: absent $=0$; present, separating metepisternal depressions $=1$; depressions separated by broad swelling $=2$. [additive]

221. Metapleuron, lateral longitudinal carina: absent $=0$; low carina laterally of metepisternal depressions present $=1$; projections at anterolateral corners of metepisternal depressions present $=2$. [additive]

222. Metapleuron, ventral transverse carina: absent or weakly developed $=0$; transverse carina anterior to metacoxal foramina present $=1$.

223. Metapleuron, area anterior to paracoxal ridge/sulcus: reduced medially $=0$; well developed $=1$.

224. Metapleuron, anterior paracoxal sulci/ridges: absent $=0$; present $=1$.

225. Metapleuron, posterior paracoxal ridge: absent $=0$; present $=1$.

226. Metapleuron, anterior paracoxal ridge: not reaching metapleural apodemes $=0$; extending to metapleural apodemes $=1$; continuous with marginal metapleural apodeme, separate from metapleural apodeme $=2$. [nonadditive]

227. Metapleuron, metapectal plates: absent $=0$; low lobe present laterally on anterior paracoxal ridge $=1$.

228. Metapleuron, metacoxal foramina: well separated from mesocoxal foramina $=0$; adjacent to mesocoxal foramina, ventral metepisternum reduced $=1$.

229. Metapleuron, median coxal articulation: reduced, at most developed as low swelling $=0$; articulation point well developed $=1$. 230. Metapleuron, median coxal articulation position: ventromedial to lateral articulation, axis of movement oblique $=0$; approximately ventral to lateral articulation, axis of movement vertical $=1$.

231. Metapleuron, lateral coxal articulation: exposed, visible laterally $=0$; concealed in lateral view $=1$.

232. Metapleuron, articulation notch: absent or weakly developed $=0$; notch in foraminal rim at metacoxal lateral articulation well developed $=1$

233. Metafurca, metafurcal pit position: closer to metacoxal foramina than to anterior margin of metapectus $=0$; closer to anterior margin of metapectus than to metacoxal foramina $=1$.

234. Metafurca, number of metafurcal pits: one $=0$; two $=1$.

235. Metafurca, position: metafurcal arms arise posteriorly on metadiscrimen $=0$; metafurcal arms arising at or close to anterior end of metadiscrimen $=1$.

236. Metafurca, furca-discrimen configuration: adjacent, arising from discrimen $=0$; widely separate, not converging, detached from discrimen $=1$.

237. Metafurca, connection to mesofurca: separate from mesofur$\mathrm{ca}=0$; fused with mesofurca for some distance $=1$.

238. Metafurca, anterior metafurcal arm: elongate, at most slightly shorter than lateral $\mathrm{arm}=0$; reduced, considerably shorter than lateral $\operatorname{arm}=1$ 
239. Metafurca, lateral metafurcal arm: short $=0$; elongate, extending towards metapleural apodeme $=1$; fused with metapleural apodeme $=2$. [additive]

\section{Hind leg (thorax)}

240. Hind leg, trochantins: absent $=0$; present $=1$.

241. Hind leg, size of coxa: short, less than $3 / 4$ length of hind femur + trochanter $=0$; elongate, more than $3 / 4$ length of hind femur + trochanter $=1$.

242. Hind leg, femoral spines: absent or weakly developed $=0$; at least one distinct spine present ventrally $=1$.

243. Hind leg, tibial preapical spurs: absent $=0$; present $=1$.

244. Hind leg, tibial brush: absent $=0$; dense brush of setae present on at least part of median side $=1$.

245. Hind leg, tarsal plantulae: absent $=0$; present $=1$.

\section{Abdominal tergum 1 (= propodeum in apocrita)}

246. Propodeum/T1 medially: divided $=0$; continuous $=1$.

247. Propodeum, metapostnotum association: separated by unsclerotized line, connection movable $=0$; immovably fused $=1$.

248. Propodeum, median antecostal projections: absent $=0$; one projection present anteriorly and posterad antecosta $=1$; several projections present anteriorly and posterad antecosta $=2$. [additive]

249. Propodeum, lateral antecostal projections: absent $=0$; present anteriorly and posterad antecosta $=1$.

250. Propodeum, metaphragma: absent $=0$; present only laterally $=1$; present, continuous medially $=2$. [additive]

251. Propodeum, metalaterophragmal lobes: weakly developed or absent $=0$; well developed $=1$.

252. Propodeum, metaphragma-metapleural apodeme configuration: separate $=0 ;$ metaphragma and metapleural apodeme fused $=1$.

253. Propodeum, metapostnotum: continuous medially $=0$; subdivided medially $=1$.

254. Propodeum, median projection: absent $=0$; distinct projection present medially $=1$.

255. Propodeum, median longitudinal carina: absent $=0$; present, well developed $=1$.

256. Propodeum, lateral longitudinal carina ("plica"): absent $=0$; distinct ridge dorsal to propodeal spiracle present $=1$.

257. Propodeum, propodeal spiracle configuration: elongate, slitlike $=0$; rounded $=1$.

258. Propodeum, propodeal spiracle laterally: exposed $=0$; covered by flap $=1$.

259. Propodeum, spiracle position (horizontal): not further than halfway between antecosta and $\mathrm{T} 1$ posterior margin $=0$; closer to $\mathrm{T} 1$ posterior margin than to antecosta $=1$.

260. Propodeum, spiracle position (vertical): not adjacent to propodeal-metapleuron boundary $=0$; abutting boundary $=1$.

261. Propodeum, transverse carina: absent $=0$; distinct carina present some distance from propodeal foramen $=1$.

262. Propodeum, propodeal foramen: not developed, T2 broadly attached to $\mathrm{T} 1=0 ; \mathrm{T} 1$ articulating with $\mathrm{T} 2$ but not constricted laterally $=1 ; \mathrm{T} 1$ posteriorly constricted laterally, articulating with $\mathrm{T} 2=2$. [additive]

263. Propodeum, propodeal foramen configuration: continuous with metacoxal foramina $=0$; separated from metacoxal foramina by sclerotized bridges $=1$.

264. Propodeum, position of propodeal foramen: situated posterad anterior margin of metacoxal foramen $=0$; situated at level with metacoxal foramen $=1$; dorsally, at least halfway between metacoxal foramina and metapostnotum $=2$; adjacent to antecostal sulcus, compressing sulcus medially $=3$. [additive]
265. Propodeum, propodeal foramen ventrally: straight $=0$; distinctly incurved $=1$.

266. Propodeum, propodeal foramen shelf: absent $=0$; distinct shelf extending ventrally into body cavity from foramen $=1$.

267. Propodeum, articulating teeth: absent or weakly developed $=0$; distinct teeth present $=1$.

268. First abdominal sternum: absent or reduced $=0$; present $=1$.

\section{Metasoma ( = abdominal segments distal to first in non- apocritans)}

269. Petiole, T2 and S2 configuration: separate $=0$; fused, at least anteriorly $=1$.

270. Petiole, posteriorly: wider than anterior foramen $=0$; narrow, approximately same width as anterior foramen $=1$.

271. Petiole, articulating condyle: reduced or absent, petiolar foramen subcircular $=0$; well developed, T-shaped in anterior view $=1$.

272. Petiole, anterior width: not broad, condyle occupying at least $1 / 2$ of anterior width $=0$; broad, condyle less than $1 / 3$ of anterior width $=1$. 273. Petiole, transverse carina on T2: absent $=0$; present, situated just posterad articulation $=1$.

274. Petiole, T2 longitudinal internal carina: absent $=0$; carina present posteriorly, externally indicated by furrow $=1$.

275. Petiole, S2: at least partly sclerotized $=0$; membranous medioventrally $=1$.

276. Petiole, S2 posteriorly: equally sclerotized or membranous throughout $=0$; less heavily sclerotized posteriorly for at least half the length of $\mathrm{T} 2=1$.

277. Petiole, transverse carina anteriorly on $\mathrm{S} 2$ : absent $=0$; transverse carina posterad sensillar patches present $=1$.

278. Petiole, longitudinal carina anteriorly on $\mathrm{S} 2$ : absent $=0$; present posterad anterior margin $=1$.

\section{Mesosomal muscles}

279. Muscles, median pronoto-prophragmal muscle: absent $=0$; present $=1$.

280. Muscles, site of origin of the dorsal pronoto-procoxal muscle: from along the dorsal margin of the pronotum $=0$; distinctly ventrad the dorsal margin of the pronotum $=1$; from the ventral surface of the anterior thoracic spiracle occlusor muscle apodeme $=2$. [nonadditive]

281. Muscles, ventral pronoto-procoxal muscle: absent $=0$; present $=1$.

282. Muscles, pronoto-mesobasalar muscle: absent $=0$; present $=1$. 283. Muscles, pronoto-profurcal muscle: absent $=0$; present $=1$.

284. Muscles, pronoto-third axillary sclerite of forewing muscle: absent $=0$; present $=1$.

285. Prepectus, anterior spiracle occlusor muscle: arising from free prepectus $=0$; arising from mesopleuron $=1$; arise from pronotum $=2$. [nonadditive]

286. Muscles, site of pronotal origin of the anterior thoracic spiracle occlusor muscle: originating at least partly from the occlusor muscle apodeme $=0$; originating from the wall of the pronotum $=1$.

287. Muscles, lateral metapleuro-postoccipital muscle: absent $=0$; present $=1$.

288. Muscles, propleural arm-postoccipital muscle: absent $=0$; present $=1$.

289. Muscles, propleural arm-protrochanteral muscle: absent $=0$; present $=1$.

290. Muscles, mesofurco-propleural arm muscle: absent $=0$; present $=1$.

291. Muscles, profurco-prophragmal muscle: absent $=0$; present $=1$. 292. Muscles, origin of median profurco-procoxal muscle: from the posteroventral part of the profurca $=0$; from the ventral part of the propleural arm $=1$. 
293. Muscles, profurco-protrochanteral muscle: absent $=0$; present $=1$.

294. Muscles, prospinasterno-profurcal muscle: absent $=0$; present $=1$.

295. Muscles, dorsal mesofurco-profurcal muscle: absent $=0$; present $=1$.

296. Muscles, prospinasterno-procoxal muscle origin: from independent prospinasternum $=0$; from anterior mesopleural margin $=1$; from ventral pronotal sclerotization $=2$; from independent prepectus $=3$. [nonadditive]

297. Muscles, mesonoto-mesobasalar muscle: absent $=0$; present $=1$.

298. Muscles, mesonoto-mesolaterophragmal muscle: absent $=0$; present $=1$.

299. Muscles, mesonoto-mesocoxal muscle: absent $=0$; present $=1$. 300. Muscles, anterior mesonoto-mesotrochanteral muscle: absent $=$ 0 ; present $=1$.

301. Muscles, posterior mesonoto-mesotrochanteral muscle: absent $=$ 0 ; present $=1$.

302. Muscles, anterior mesonoto-metanotal muscle: absent $=0$; present $=1$.

303. Muscles, posterior mesonoto-metanotal muscle: the two bands of the paired muscle insert medially on the metanotum $=0$; the two bands of the paired muscle insert laterally on the metanotum $=1$.

304. Muscles, site of origin of second mesopleuro-mesonotal muscle: from the mesopleural ridge or posterior to the mesopleural ridge from the mesopleural arm $=0$; anterior to the mesopleural ridge or from the wall of the mesopleuron sometimes at least partly from the mesopleural apodeme $=1$.

305. Muscles, intersegmental membrane-mesobasalar muscle absent $=$ 0 ; present $=1$.

306. Muscles, mesocoxo-mesobasalar muscle: absent $=0$; present $=1$.

307. Muscles, mesotrochantero-mesobasalar muscle: absent $=0$; present $=1$.

308. Muscles, mesopleuro-mesosubalar muscle: absent $=0$; present $=1$.

309. Muscles, mesocoxo-mesosubalar muscle: absent $=0$; present $=1$. 310. Muscles, mesofurco-mesopleural muscle: absent $=0$; present $=$ 1.

311. Muscles, site of origin of the mesopleuro-mesocoxal muscle: originating from the anterior surface of the mesopleural ridge $=0$; originating from the wall of the mesopleuron sometimes partly from the mesopleural apodeme $=1$.

312. Muscles, mesopleuro-third axillary sclerite of hind wing muscle: absent $=0$; present $=1$.

313. Muscles, posterior mesofurco-mesolaterophragmal muscle: absent $=0$; present $=1$.

314. Muscles, lateral mesofurco-mesotrochanteral muscle: absent $=0$; present $=1$.

315. Muscles, medial mesofurco-mesotrochanteral muscle: absent $=0$; present $=1$.

316. Muscles, site of origin of the median mesofurco-mesotrochanteral muscle: originating submedially from the lateral part of the mesofurcal arm $=0$; originating from the mesofurcal bridge or from the anterior mesofurcal arm $=1$.

317. Muscles, mesofurco-metabasalar muscle: absent $=0$; present $=1$. 318. Muscles, mesospinasterno-metafurcal muscle: absent $=0$; present $=1$.

319. Muscles, metanoto-metabasalar muscle: absent $=0$; present $=1$. 320. Muscles, median metapleuro-metanotal muscle: absent $=0$; present $=1$

321. Muscles, site of origin of the median metapleuro-metanotal muscle: originating anterior to the paracoxal ridge $=0$; originating posterad the paracoxal ridge $=1$.

322. Muscles, metalaterophragmo-metafurcal muscle: absent $=0$; present $=1$.
323. Muscles, metanoto-metalaterophragmal muscle: absent $=0$; present $=1$.

324. Muscles, anterior metanoto-metacoxal muscle: absent $=0$; present $=1$.

325. Muscles, posterior metanoto-metacoxal muscle: absent $=0$; present $=1$.

326. Muscles, metanoto-metatrochanteral muscle: absent $=0$; present $=1$.

327. Muscles, site of origin of the anterior metapleuro-metabasalare muscle: from anterior to the paracoxal ridge, but posterior to the anterior margin of the metapleuron $=0$; from the wall of the fused meso-metapectus $=1$.

328. Muscles, lateral metapleuro-metabasalar muscle: absent $=0$; present $=1$.

329. Muscles, posterior metapleuro-metabasalare muscle: absent $=0$; present $=1$.

330. Muscles, metacoxo-metabasalar muscle: absent $=0$; present $=1$. 331. Muscles, metacoxo-metasubalar muscle: absent $=0$; present $=1$. 332. Muscles, anterior metapleuro-metafurcal muscle: absent $=0$; present $=1$.

333. Muscles, posterior metapleuro-metafurcal muscle: absent $=0$; present $=1$.

334. Muscles, lateral metapleuro-metacoxal muscle: originating from the metapleural apodeme and sometimes from the metapleuron ventrad the metapleural apodeme, site of origin $=0$; originating exclusively from the paracoxal ridge $=1$.

335. Muscles, site of origin of the lateral metapleuro-metacoxal muscle: does not extend to the propodeum $=0$; extends to the propodeum $=1$. 336. Muscles, metapleuro-propodeal muscle: absent $=0$; present $=1$. 337. Muscles, metasterno-second abdominal sternal muscle: absent $=0$; present $=1$.

338. Muscles, site of origin of the metapleuro-metatrochanteral muscle: does not extend to the propodeum $=0$; extending to the propodeum $=1$.

339. Muscles, second abdominal sternal-metacoxal muscle: absent $=0$; present $=1$.

340. Muscles, propodeo-second abdominal segment muscle: absent $=0$; present $=1$.

341. Muscles, site of origin of the dilator muscle of the propodeal spiracle: originating just dorsad the lateral metacoxal articulation $=0$; originating from the metapleural apodeme, anterior to the propodeal spiracle $=1$; originating from the propodeum on the level of the propodeal foramen $=2$. [nonadditive]

\section{Wings}

342. Forewing, sculpture of retinaculum: with microspicules $=0$; with crenulae $=1 ;$ smooth $=2$. [nonadditive]

343. Forewing, costal and radial vein fusion: not fused $=0$; fused along their lengths $=1$.

344. Forewing, cubital $(\mathrm{Cu})$ vein shape: bent sharply towards the posterior margin, apical to $1 \mathrm{~m}-\mathrm{cu}$ crossvein $=0$; not bent sharply towards the posterior margin, apical to $1 \mathrm{~m}$-cu crossvein $=1$.

345. Forewing, costal (C) vein presence: complete as a tubular vein $=0$; absent or present but not complete as a tubular vein $=1$.

346. Forewing, stigma presence: present $=0$; absent $=1$.

347. Forewing, subcostal (SC) vein presence: present as a longitudinal vein $=0$; present as an apparent crossvein only $=1$; absent $=2$. [nonadditive]

348. Forewing, second branch of radial sector (RS2) vein presence: present $=0$; absent $=1$.

349. Forewing, anal crossvein (a) presence: present $=0$; absent $=1$. 350 . Forewing, nygmata (sensory spots) on wing membrane (in second submarginal cell): present $=0$; absent $=1$.

351. Hind wing, costal (C) vein presence: present, and at least half as long as distance to costal break $=0$; absent or reduced to a small stub at wing base $=1$. 
352. Hind wing, non-apical hamuli, presence: present and hooked or thick and highly sclerotized $=0$; absent $=1$.

353. Hind wing, subcostal (SC) vein presence: present $=0$; absent $=1$. 354. Hind wing, number of rs-m crossveins: three $=0$; two $=1$; none or one $=2$. [nonadditive]

355. Hind wing, $\mathrm{m}-\mathrm{cu}$ crossvein presence: present $=0$; absent $=1$.

356. Hind wing, medial $(\mathrm{M})$ vein and cubital $(\mathrm{Cu})$ vein fusion: separated basally $=0$; not separated basally $=1$.

357. Hind wing, costal margin: not broadly curved $=0$; broadly curved $=1$.

358. Hind wing, costal trough extending from base to hamuli: present $=0$; absent $=1$.

359. Hind wing, fusion of radial (R) and costal (C) veins posterad hamuli, cell presence: $\mathrm{R}$ and $\mathrm{C}$ separated and forming a small cell posterad hamuli separating and re-fusing distal to hamuli, thus forming a small cell $=0 ; \mathrm{R}$ and $\mathrm{C}$ not separated posterior to hamuli, small cell not present $=1$.

360. Hind wing, microspicules posterad hamuli: present $=0$; absent $=1$.

361. Hind wing, presence of guide setae or spines posterior to hamuli: absent $=0$; present $=1$.

362. Hind wing, presence of sclerotized glabrous plate posterior to hamuli: absent $=0$; present $=1$.

\section{Legs}

363. Mesotibial apical spurs: two $=0$; one $=1$; none $=2$. [nonadditive]

364. Tip of tibial spurs: pointed and sclerotized $=0$; blunt and with a smooth (membranous) area $=1$.

365. Presence of velum on calcar: velum present $=0$; velum absent $=1$.

366. Velum appearance: smooth and with smooth rim $=0$; smooth but with serrated rim $=1$; smooth but with a fine comb of socketed setae along edge $=2$; with a spinose or ribbed surface $=3$. [nonadditive]

367. Anterior basitarsus: with one row of paddle-shaped setae $=0$; with more than one row of paddle-shaped setae $=1$; with ordinary setae $=2$. [nonadditive]

368. Inner posterior metatibial spur: simple $=0$; modified into a calcar $=1$.

369. Mesotibial apical sensillum: present $=0$; absent $=1$.

370. Inner posterior mesotibial spur: simple $=0$; modified into a calcar $=1$.

371. Foretibial apical sensillum: present $=0$; absent $=1$.

372. Metatibial apical sensillum: present $=0$; absent $=1$.

373. Midleg tibial comb: absent $=0$; present as row of similarly sized, peg-like setae arranged in a row $=1$.

\section{Abdomen}

374. Abdominal tergum 3 (metasomal 2) presence of laterotergites: not separated by a longitudinal fold into lateral and medial tergites $=0$; separated by a longitudinal fold into lateral and medial tergites $=1$.

375. Interleaving of abdominal terga and sterna 4-5 (metasomal terga 3-4): not interleaved. If in contact, terga completely overlying preceding sterna $=0$; abdominal tergum 4 lying under sternum 3 laterally (metasomal tergum 3 under sternum 2) $=1$.

376. Presence of a glymma (laterope): absent $=0$; present $=1$.

377. Articulation between abdominal tergum 2 and tergum 3 (metasomal 1 and 2): terga 2-3 not hinged sub-medially =0; terga $2-3$ hinged submedially $=1$.

378. Spiracles on abdominal terga 2-8 (metasomal 1-7): well developed on most terga $=0$; reduced or absent on $2-7$, present or absent on $8=1$.

379. Second abdominal sternum (first metasomal): entirely evenly sclerotized $=0$; evenly sclerotized anteriorly, but posteriorly with membranous areas, or more weakly sclerotized areas $=1$.

380. Abdominal sternum 1, presence: present $=0$; absent $=1$.

381. Abdominal tergum 2 (metasomal 1) overlapping abdominal tergum 3 (metasomal 2): overlapping $=0$; not overlapping $=1$.

\section{Miscellaneous}

382. Male thoracic muscles diploid: haploid $=0$; diploid $=1$.

\section{Ovipositor}

383. Position of egg exit: at or near apex of ovipositor $=0$; at or near base of ovipositor $=1$.

384. Ovipositor shape: laterally flattened $=0$; cylindrical, not laterally flattened $=1$.

385. Furcula of ovipositor: absent $=0$; present $=1$.

386. Structure of ovipositor sheaths: unsegmented $=0$; divided into two segments $=1$.

387. Valvilli presence: absent $=0$; present $=1$.

388. Second valvifer structure: not divided, pars articularis absent $=0$; subdivided, pars articularis present $=1$.

\section{Miscellaneous}

389. Meconium: not formed, feces voided continuously during larval development $=0$; meconium voided at the end of larval development $=1$.

390. Mode of parasitism: ectoparasitoid $=0$; endoparasitoid $=1$.

391. Larval food source: plants $=0$; animals $=1$.

392. Silk production: labial silk production from salivary gland secretions $=0$; no silk production from salivary glands $=1$. 


\section{Apppendix 2}

List of taxa and gene regions sampled for Hymenoptera and outgroups as discussed in text.

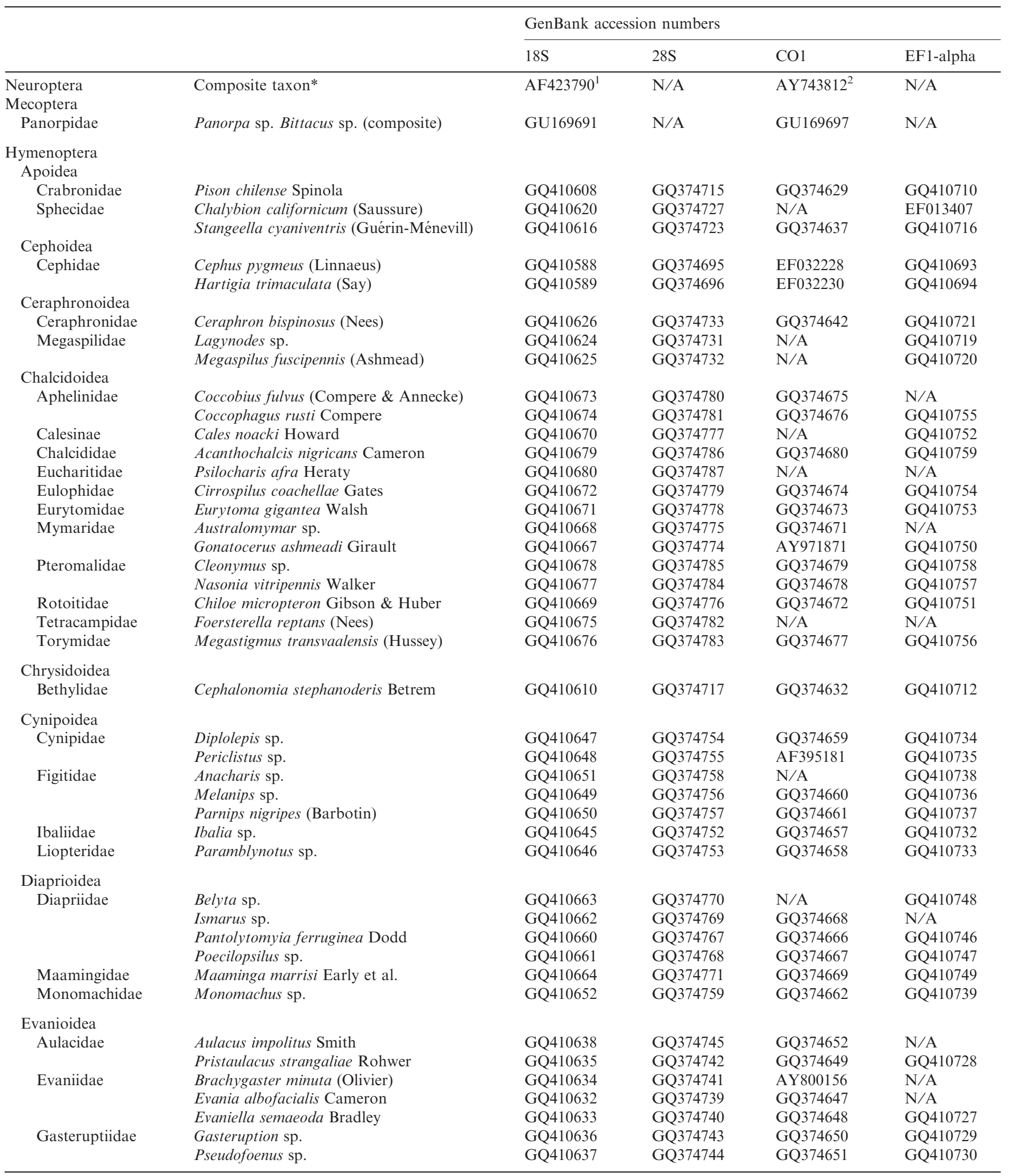




\section{Apppendix 2}

(Continued)

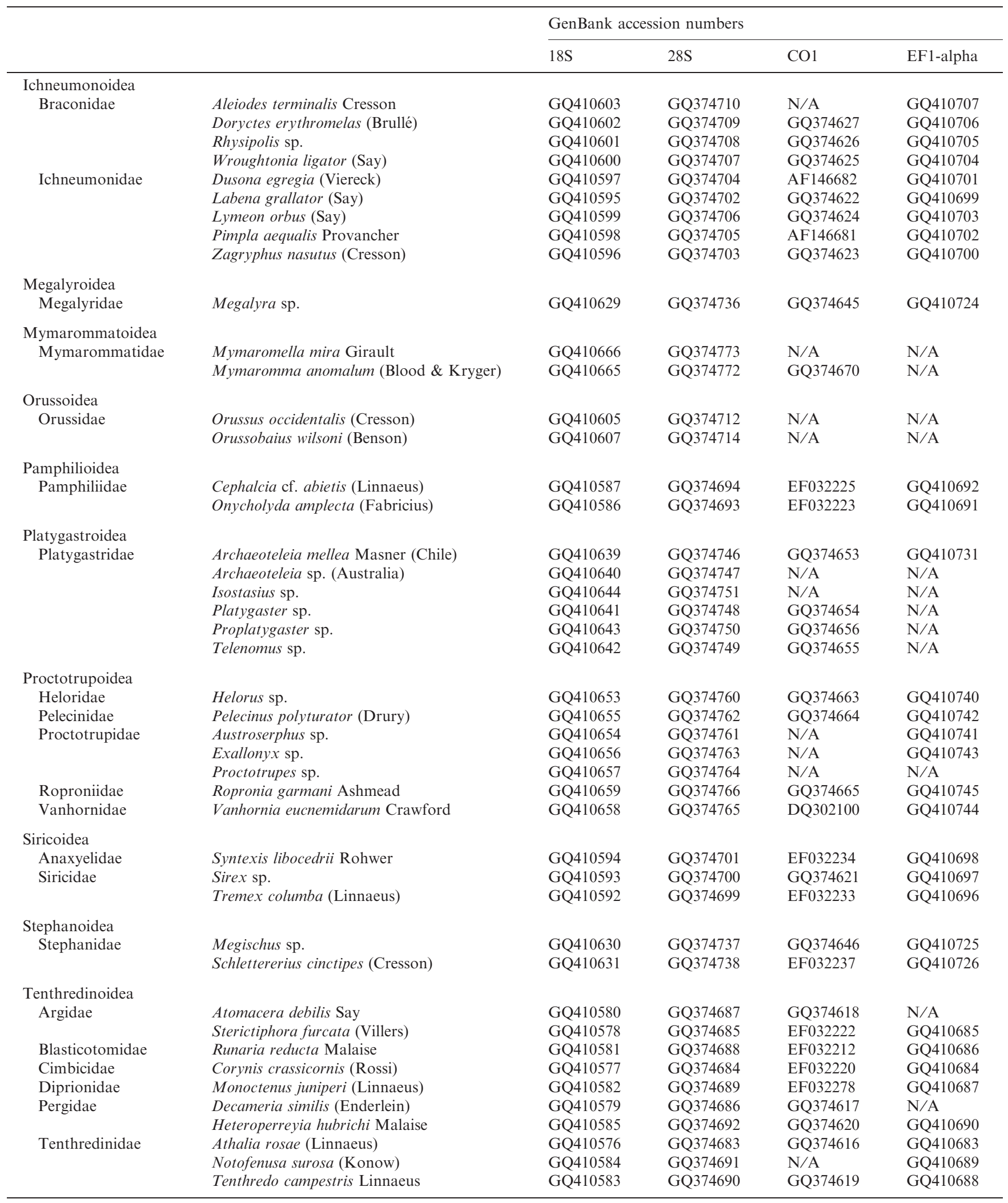




\section{Apppendix 2}

(Continued)

\begin{tabular}{|c|c|c|c|c|c|}
\hline & & \multicolumn{4}{|c|}{ GenBank accession numbers } \\
\hline & & $18 \mathrm{~S}$ & $28 \mathrm{~S}$ & $\mathrm{CO} 1$ & EF1-alpha \\
\hline \multicolumn{6}{|l|}{ Trigonaloidea } \\
\hline \multirow[t]{2}{*}{ Trigonalidae } & Orthogonalys pulchella (Cresson) & GQ410628 & GQ374735 & GQ374644 & GQ410723 \\
\hline & Taeniogonalys gundlachii (Cresson) & GQ410627 & GQ374734 & GQ374643 & GQ410722 \\
\hline \multicolumn{6}{|l|}{ Vespoidea } \\
\hline Mutillidae & Dasymutilla aureola (Cresson) & GQ410621 & GQ374728 & $\mathrm{N} / \mathrm{A}$ & EF013414 \\
\hline Rhopalosomatidae & Rhopalosoma nearcticum Brues & GQ410617 & GQ374724 & GQ374638 & GQ410717 \\
\hline Sapygidae & Sapyga pumila Cresson & GQ410612 & GQ374719 & GQ374634 & GQ410713 \\
\hline Scoliidae & Scolia verticalis Fabricius & EF012932 & EF013060 & GQ374641 & EF013507 \\
\hline Vespidae & Metapolybia cingulata (Fabricius) & GQ410613 & GQ374720 & GQ374635 & GQ410714 \\
\hline Xiphydrioidea & Derecyrta circularis Smith & GQ410591 & GQ374698 & $\mathrm{N} / \mathrm{A}$ & $\mathrm{N} / \mathrm{A}$ \\
\hline Xiphidriidae & Xiphydria prolongata (Geoffrov) & GQ410590 & GQ374697 & EF032235 & GQ410695 \\
\hline Xyeloidea & Macroxyela ferruginea (Say) & GQ410574 & GQ374681 & EF032211 & GQ410681 \\
\hline Xyelidae & Xyela julii (Brebisson) & GQ410575 & GQ374682 & EF032210 & GQ410682 \\
\hline
\end{tabular}

*Composite taxa comprised of sequences from more than one taxon follows: Hemerobiidae: ${ }^{1}$ Hemerobius sp.; Chrysopidae: ${ }^{2}$ Chrysoperla agilis Henry et al. Morphology was scored using Chrysopa sp. 